\title{
Influence of processing parameters of selective laser melting on high-cycle and very-high-cycle fatigue behaviour of Ti-6Al-4V
}

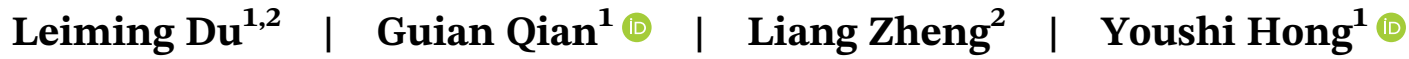

${ }^{1}$ LNM, Institute of Mechanics, Chinese Academy of Sciences, Beijing, 100190, China

${ }^{2}$ School of Science, Harbin Institute of Technology, Shenzhen, 518055, China

\section{Correspondence}

Liang Zheng, School of Science, Harbin Institute of Technology, Shenzhen 518055, China.

Email: icon_lzheng@hit.edu.cn

Youshi Hong, LNM, Institute of Mechanics, Chinese Academy of Sciences, Beijing 100190, China.

Email: hongys@imech.ac.cn

\section{Funding information}

Chinese Academy of Sciences, Grant/ Award Numbers: XDB22040503, XDB22020201; National Natural Science Foundation of China, Grant/Award Number: 11932020

\begin{abstract}
Orthogonal experiment design together with the analysis of variance was used to examine the processing parameters (laser power, scan speed, layer thickness and hatch spacing) of selective laser melting (SLM) for superior properties of SLM parts, in which nine groups of specimens of Ti-6Al-4V were fabricated. The results clarify that the influence sequence of individual parameter on the porosity is laser power $>$ hatch spacing $>$ layer thickness $>$ scan speed. Ultrasonic fatigue tests $(20 \mathrm{kHz})$ were conducted for the SLMed specimens in highcycle fatigue (HCF) and very-high-cycle fatigue (VHCF) regimes. The $S$ - $N$ data show that the fatigue strength is greatly affected by the porosity: the group with the smallest porosity percentage having the highest fatigue strength in HCF and VHCF regimes. Then, the tests on the validation group were performed to verify the optimal combination of SLM processing parameters. Moreover, the observations by scanning electron microscopy revealed that fatigue cracks initiate at lack-of-fusion defects in the cases of surface and internal crack initiation.
\end{abstract}

\section{KEYWOR D S}

orthogonal experiment design, processing parameters, selective laser melting, Ti-6Al-4V, very-

high-cycle fatigue

\section{1 | INTRODUCTION}

Additive manufacturing (AM) technology is capable of layer-by-layer fabrication of intricate and net-shaped metallic parts directly from three-dimensional computer designed schemes. ${ }^{1-5}$ Selective laser melting (SLM) is a promising AM technique to produce metallic parts used in aerospace, automotive and biomedical engineering, where geometrically complex structures of high-strength materials are widely used. In particular, Ti-6Al-4V components fabricated by SLM have gained a lot of interest due to their high specific static and fatigue strength. ${ }^{6}$

SLM process is controlled by a set of processing parameters (such as laser power, scan speed, layer thickness and hatch spacing), which have a direct influence on the mechanical properties of the fabricated parts. Some researchers have investigated the influence of SLM processing parameters on the defect formation in the AM parts. ${ }^{7-9}$ For example, Kasperovich et $\mathrm{al}^{7}$ reported that the porosity of the SLMed parts is mainly dependent on the choice of scan speed and laser power, and it is less sensitive to the hatch distance. Gong et $\mathrm{al}^{8}$ proposed an SLM process window with four types of melting zones, that is, 'fully dense', 'over-melting', 'incomplete melting' and 'overheating' resulted from different values of laser power and scan speed, which affects the defect formation. It is certain that non-optimal combination of processing parameters will cause the instability in the melting pool 
during the manufacturing process, which may lead to the formation of internal defects, such as pores, unmelted powder particles and lack-of-fusion. ${ }^{10-13}$ Such defects will definitely cause detrimental effects on the mechanical properties of the fabricated AM parts.

The influence of processing parameters on the microstructure and the related mechanical properties of the titanium parts produced by SLM has also been reported. The investigations of $\mathrm{Xu}$ et $\mathrm{al}^{14}$ and Liu et $\mathrm{al}^{15}$ showed that the static mechanical properties of the Ti$6 \mathrm{Al}-4 \mathrm{~V}$ parts by SLM are comparable to those of forged counterparts. For considering the reliability of the AM components in engineering applications, the manufactured parts should be durable not only under static loading but also under dynamic cycling, which is usually the case of many aerospace and automotive applications. $^{16,17}$ Thus, the concern of fatigue performance restricts the applications of AM parts, especially in the industries where the long-term reliability is a critical requirement. In recent years, the behaviour of low-cycle fatigue $(\mathrm{LCF})^{18,19}$ and high-cycle fatigue $(\mathrm{HCF})^{20-22}$ of AM titanium alloys (e.g., Ti-6Al-4V) has been investigated. However, just a few studies ${ }^{23,24}$ with regard to the veryhigh-cycle fatigue (VHCF) behaviour of the Ti-6Al-4V parts manufactured by SLM are available in the literature. As an example, Wycisk et $\mathrm{al}^{23}$ examined the Ti-6Al-4V specimens with stress-relieved and hot-isostatic-pressed (HIP) conditions to investigate the crack initiation site, mean stress sensitivity and overall fatigue performance. Günther et $\mathrm{al}^{24}$ also showed that the VHCF performance of the SLM-processed and HIP-treated specimens is superior to that of its counterparts and similar to the conventional material. Recently, Qian et $\mathrm{al}^{25}$ revealed the effect of building orientation on the VHCF response of Ti-6Al-4V specimens manufactured by SLM with three building orientations $\left(0^{\circ}, 45^{\circ}\right.$ and $\left.90^{\circ}\right)$, showing that the fatigue performance decreases with the building orientation from $0^{\circ}$ to $90^{\circ}$. In addition, the VHCF behaviour of other alloys made by SLM is also available in the literature. For instance, Tridello et $\mathrm{al}^{26}$ showed that annealing at $320^{\circ} \mathrm{C}$ induces the spheroidization of the $\mathrm{Si}$ network, which enhances the ductility but has a negative effect on the VHCF response of an SLMed AlSi10Mg alloy; however, for the case of heating at $244^{\circ} \mathrm{C}$, the as-built microstructure is not changed and the reduction of the residual stress results in the enhancement of VHCF performance.

However, the effect of processing parameters on the VHCF response of Ti-6Al-4V alloy has not yet been investigated. Thus, to establish the relationship among processing parameters, manufactured structure and resulted mechanical properties especially the VHCF performance of the AM parts by SLM is an important and challenging goal of producing high-quality AM parts for engineering applications.

Aforementioned, an optimal combination of processing parameters is a key issue for the production of high-quality AM parts with good mechanical properties including $\mathrm{HCF}$ and VHCF performance. For identifying the sensitivity of each processing parameter to the mechanical behaviour of AM parts and finding the optimal combination of processing parameters, the method of orthogonal experiment design (OED) or Taguchi experiment design is a promising approach to solve the problem. OED is an experiment design method to efficiently investigate the multifactor with multilevel sampling problem, which just assigns limited and representative experimental groups from a large test set according to the orthogonality. ${ }^{27-29}$ In practice, OED has been used to investigate the predominant effects of multiple parameters with the fewest experimental groups.

Therefore, the aim of this paper is to investigate the effect of SLM processing parameters on the HCF and VHCF behaviour of a Ti-6Al-4V produced by SLM. The method of OED with the analysis of variance (ANOVA) was utilized in the analysis and optimization of the SLM processing parameters of laser power, layer thickness, scan speed and hatch spacing. The porosities of the specimens resulted from the defects due to different combinations of processing parameters were measured. The mechanical properties especially the $\mathrm{HCF}$ and VHCF behaviour of SLMed Ti-6Al-4V specimens were comprehensively investigated. In addition, the fatigue failure morphologies were examined via scanning electron microscopy (SEM). Thus, the sensitivity of the four SLM processing parameters to the mechanical behaviour especially to the HCF and VHCF performance was clarified and the optimal combination of such processing parameters was obtained. As a consequence, a validation specimen group was prepared and the test results of porosity, tensile properties and fatigue performance validate the optimal combination of the SLM processing parameters.

\section{2 | MATERIALS AND EXPERIMENTAL METHODS}

\section{1 | Materials and SLM process}

The specimens were manufactured by an SLM machine (HBD-200), which was equipped with a fibre laser device with the maximum power of $200 \mathrm{~W}$ to selectively fuse the powder bed. During the SLM process, the building chamber was shielded by high purity argon to prevent oxidation of melted tracks. As shown in Figure 1A, a uniform 'bed' of powder was first deposited and then the specific 

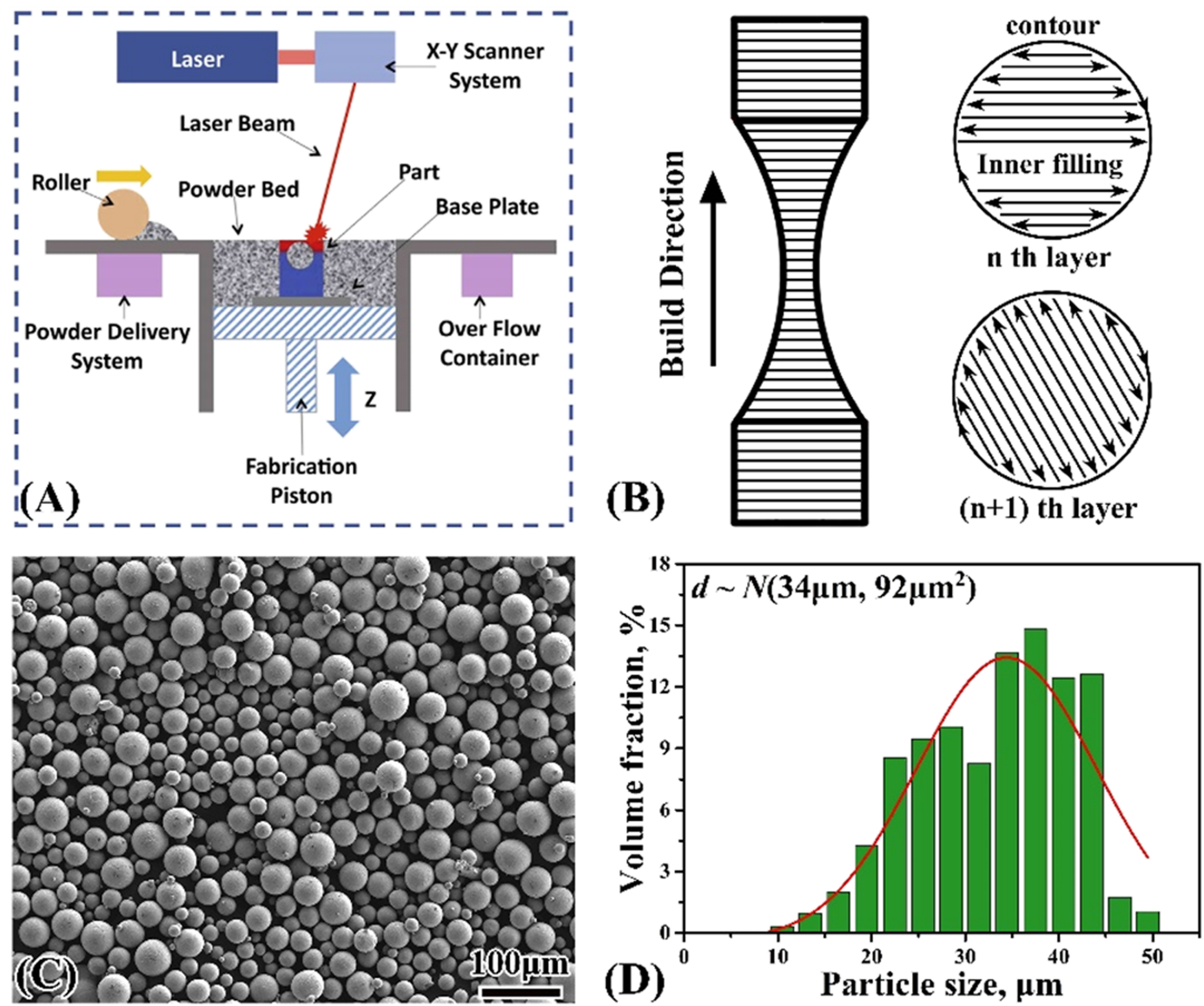

F I G U RE 1 (A) Schematic of selective laser melting (SLM) process, ${ }^{30}$ (B) build direction and processing strategy of inner filling and contour scanning for a vertically built specimen, (C) scanning electron microscopy (SEM) image of the used Ti-6Al-4V powder and (D) powder particle size distribution [Colour figure can be viewed at wileyonlinelibrary.com]

regions of the bed were melted by the laser beam. After scanning one layer, the platform was lowered by one layer thickness as a vertical increment, and another layer of powder was deposited on the top of the previously solidified layer. Each specimen was manufactured by a scanning procedure including an inner hatch/filling process and a contour scan process. The contour scanning with just one scan line was used to define the outer shape prior to the inner hatching of each layer, and the thickness of contour scan is negligible compared to the inner hatching domain. All specimens were produced in the vertical orientation and the laser travel direction was rotated by $60^{\circ}$ for the subsequent layer to gain a relatively isotropic material, which is schematically illustrated in Figure 1B. After repeating this depositing and melting process, the required specimen can be built. Thereafter, in order to relieve the residual stress generated in the fabrication process, the SLMed specimens were annealed by heating at $600^{\circ} \mathrm{C}$ for $2 \mathrm{~h}$ then cooled in a vacuum furnace with a constant supply of argon gas. Finally, all specimens were polished to remove surface defects due to partially melted powder particles.
The Ti-6Al-4V powder produced by gas atomization in argon atmosphere was used in this investigation, which is with the chemical composition (wt.\%) of 6.40 $\mathrm{Al}, 4.10 \mathrm{~V}, 0.01 \mathrm{C}, 0.19 \mathrm{Fe}, 0.01 \mathrm{~N}, 0.11 \mathrm{O}$ and balance Ti. Figure $1 \mathrm{C}$ is an SEM image showing the Ti-6Al-4V powder particles, which are generally spherical and occasionally some large ones have so-called 'satellite' particles with the diameter smaller than $10 \mu \mathrm{m}$. The small satellites are mostly spherical shape and may contribute to a better flow ability and a higher apparent density. ${ }^{31}$ Based on the observed SEM images, the size distribution of powder particles was measured by using Image-Pro Plus 6.0 software. As shown in Figure 1D, the mean diameter of the used Ti-6Al-4V powders (D50) is $34 \mu \mathrm{m}$, which was measured from about 900 particles.

\section{2 | Design of experiments}

Energy density $E\left(\mathrm{~J} \mathrm{~mm}^{-3}\right)$ is a characteristic parameter for the average applied energy per volume of material 
during layer scanning, which is expressed by Equation 1 for SLM processing ${ }^{32}$ :

$$
E=\frac{P}{v \cdot h \cdot t},
$$

where $P$ is laser power $\left(\mathrm{J} \mathrm{s}^{-1}\right), v$ is scan speed $\left(\mathrm{mm} \mathrm{s}^{-1}\right), h$ is hatch spacing $(\mathrm{mm})$ and $t$ is layer thickness $(\mathrm{mm})$. All these processing parameters of $P, v, h$ and $t$ are significant factors controlling the related SLM process. In this investigation, an $\mathrm{OED}^{27-29}$ was used for the purpose of optimizing the processing parameters (laser power, scan speed, layer thickness and hatch spacing) for obtaining the better mechanical properties of the SLMed Ti-6Al-4V parts.

The method of OED used in this investigation contained the following procedure. First, select proper quantity of each concerned processing parameter. Second, select proper orthogonal array to conduct the experiments. Third, analyse the obtained results by means of the range analysis with Minitab software. Lastly, obtain the optimal combination of processing parameters by using Minitab software. In brief, the aim of using OED is to optimize the laser processing parameters so as to obtain the AM parts with low porosity and superior mechanical properties. In this investigation, four

TA B LE 1 Factors and levels of present orthogonal experiment design (OED)

\begin{tabular}{ll}
\hline Factor & Level \\
\hline Laser power, $P(\mathrm{~W})$ & $120,160,200$ \\
\hline Layer thickness, $t(\mu \mathrm{m})$ & $30,45,60$ \\
\hline Scan speed, $v\left(\mathrm{~mm} \mathrm{~s}^{-1}\right)$ & $800,1000,1200$ \\
\hline Hatch spacing, $h(\mathrm{~mm})$ & $0.07,0.10,0.13$ \\
\hline
\end{tabular}

processing parameters of laser power, scan speed, layer thickness and hatch spacing were selected for analyses. The selected factors (parameters) with given levels for the OED are listed in Table 1, which is a four-factor threelevel OED. The present OED contains nine groups of experiments, and the test conditions for each experimental group are listed in Table 2. Note that in Table 2, the scan speed is in a descending manner, which is based on the consideration of the proper combinations of the four factors, and the use of ascending or descending sequence of the levels has no effect on the related OED process. For the nine groups of parameter combinations, the input energy density $E$ is readily calculated by Equation 1, and the results are also listed in Table 2.

The method of ANOVA was used to analyse the influence extent in sequence of all concerned factors in terms of the density (or porosity) of the specimens manufactured by SLM and also to determine which factor or parameter has the most significant effect. The parameters used in ANOVA were calculated by the following equations:

$$
T=\sum_{i=1}^{9} \sum_{t=1}^{3} x_{i t}
$$

$$
S_{\mathrm{A}}=\frac{1}{9} \sum_{j=1}^{3} K_{m j}^{2}-\frac{T^{2}}{27},
$$

$$
S_{\mathrm{E}}=\sum_{i=1}^{9} \sum_{t=1}^{3} x_{i t}^{2}-\frac{1}{3} \sum_{i=1}^{9}\left(\sum_{t=1}^{3} x_{i t}\right)^{2} \text {, }
$$

\begin{tabular}{|c|c|c|c|c|c|c|c|c|c|}
\hline Group No. & $P(W)$ & $t(\mu \mathrm{m})$ & $v\left(\mathrm{~mm} \mathrm{~s}^{-1}\right)$ & $h(\mathrm{~mm})$ & $E\left(\mathrm{~J} \mathrm{~mm}^{-3}\right)$ & $R_{\mathrm{D}}(\%)$ & $\sigma_{\mathbf{y}}(\mathrm{MPa})$ & $\sigma_{\mathbf{u}}(\mathrm{MPa})$ & $\varepsilon_{\mathrm{t}}(\%)$ \\
\hline 1 & 120 & 30 & 1200 & 0.07 & 47.6 & $2.85 \pm 0.30$ & $1176 \pm 73$ & $1198 \pm 75$ & $1.7 \pm 0.23$ \\
\hline 2 & 120 & 45 & 1000 & 0.10 & 26.7 & $5.18 \pm 0.68$ & $1117 \pm 31$ & $1143 \pm 40$ & $1.6 \pm 0.14$ \\
\hline 4 & 160 & 30 & 1000 & 0.13 & 41.0 & $1.20 \pm 0.10$ & $1135 \pm 25$ & $1198 \pm 5$ & $1.6 \pm 0.24$ \\
\hline 5 & 160 & 45 & 800 & 0.07 & 63.5 & $0.83 \pm 0.13$ & $1189 \pm 43$ & $1228 \pm 30$ & $2.8 \pm 0.50$ \\
\hline 7 & 200 & 30 & 800 & 0.10 & 83.3 & $0.53 \pm 0.15$ & $1018 \pm 20$ & $1075 \pm 34$ & $2.4 \pm 0.36$ \\
\hline 8 & 200 & 45 & 1200 & 0.13 & 28.5 & $4.73 \pm 1.13$ & $960 \pm 9$ & $998 \pm 10$ & $1.2 \pm 0.05$ \\
\hline 9 & 200 & 60 & 1000 & 0.07 & 47.6 & $1.28 \pm 0.23$ & $1089 \pm 15$ & $1102 \pm 43$ & $1.6 \pm 0.32$ \\
\hline $10^{\mathrm{a}}$ & 160 & 30 & 1000 & 0.07 & 76.2 & $0.20 \pm 0.05$ & $1045 \pm 5$ & $1200 \pm 10$ & $4.0 \pm 0.20$ \\
\hline
\end{tabular}

T A B L E 2 Parameter values, resulted porosities and tensile properties of tested Ti-6Al-4V specimens by selective laser melting (SLM)

Note: The definition of porosity $R_{\mathrm{D}}$ is given in Section 2.3, and the results are described in Section 3.1. Tensile test is described in Section 2.3, and tensile properties of yield strength $\sigma_{\mathrm{y}}$, ultimate strength $\sigma_{\mathrm{u}}$ and total elongation $\varepsilon_{\mathrm{t}}$ are described in Section 3.2.

${ }^{a}$ Group 10 is the validation group and is described in following sections. 
where $T$ is the sum of porosity data, $S_{\mathrm{A}}$ is the sum of squares correlated to the test factor $A, S_{\mathrm{T}}$ is the sum of squares of the variance, $S_{\mathrm{E}}$ is the sum of squares of the errors correlated to all test factors, $x_{i t}$ is the $t$ th measured porosity of the $i$ th group and $K_{m j}$ is the sum of the experimental data corresponding to the $m$ th level and $j$ th factor. The factors of $A$ are laser power, layer thickness, scan speed and hatch spacing. Here, the two basic assumptions for implementing ANOVA, that is, the normality and the homoscedasticity of the dependent variables, were checked by Shapiro-Wilk test and Levene test, ${ }^{33}$ respectively, and the results indicated that the selected parameters satisfy the required normality and homoscedasticity.

\section{3 | Experimental procedure}

The Ti-6Al-4V specimens produced by SLM contain defects, and the production quality is evaluated in terms of the porosity of the manufactured specimens. Thus, the density of a given sample cut from a specimen was measured by using Archimedes method. ${ }^{8}$ For each group, the average value was obtained from three samples of the group. The measured density was then compared with the nominal density of the defect-free counterpart to obtain the porosity of the given group with Equation 6:

$$
R_{\mathrm{D}}=1-\frac{\rho_{\mathrm{e}}}{\rho_{\mathrm{n}}}
$$

where $R_{\mathrm{D}}$ is porosity, $\rho_{\mathrm{e}}$ is measured density and $\rho_{\mathrm{n}}$ is nominal density. It is evident that the lower the measured density, the larger the porosity. Then, the value of $R_{\mathrm{D}}$ was regarded as a characteristic quantity to evaluate the importance of the tested factors. In addition, the porosity or defects was also characterized by $2 \mathrm{D}$ image observations of optical microscopy (OM) in both horizontal and longitudinal cross sections, that is, perpendicular and parallel to the SLM building direction, respectively. For OM examinations, the samples were ground by using $\mathrm{SiC}$ grinding papers down to 2000 grit size and then polished with $\mathrm{SiO}_{2}-\mathrm{H}_{2} \mathrm{O}_{2}$ polishing compound.

Monotonic tensile tests for the nine group specimens were conducted in a hydraulic servo testing machine with each group containing four specimens. The loading rate of the monotonic tension was $0.1 \mathrm{~mm} \mathrm{~min}^{-1}$. The geometry with the dimensions of the tensile specimen is shown in Figure 2A. Ultrasonic fatigue tests were performed at room temperature on a Lasur GF20-TC device, with a resonance frequency of $20 \mathrm{kHz}$, which requires that the resonant frequency of the specimen be equal to the input incitation frequency $(20 \mathrm{kHz} \pm 500 \mathrm{~Hz})$ of the ultrasonic piezoelectric ceramic resonator. The stress ratio $R$ was -1 for all fatigue tests. During the ultrasonic fatigue testing, compressive air was used to cool the specimen to eliminate the temperature rise of the specimen during testing. When a specimen was loaded beyond $1 \times 10^{9}$ cycles without failure, the test would be terminated and the unbroken specimen would be labelled as a run-out case. The specimens for ultrasonic fatigue testing are hourglass shape and the geometry with the dimensions of the specimen is shown in Figure 2B. Fracture surfaces of all failed specimens were examined via a high-resolution fieldemission SEM (FEI QUANTA 200 FEG).
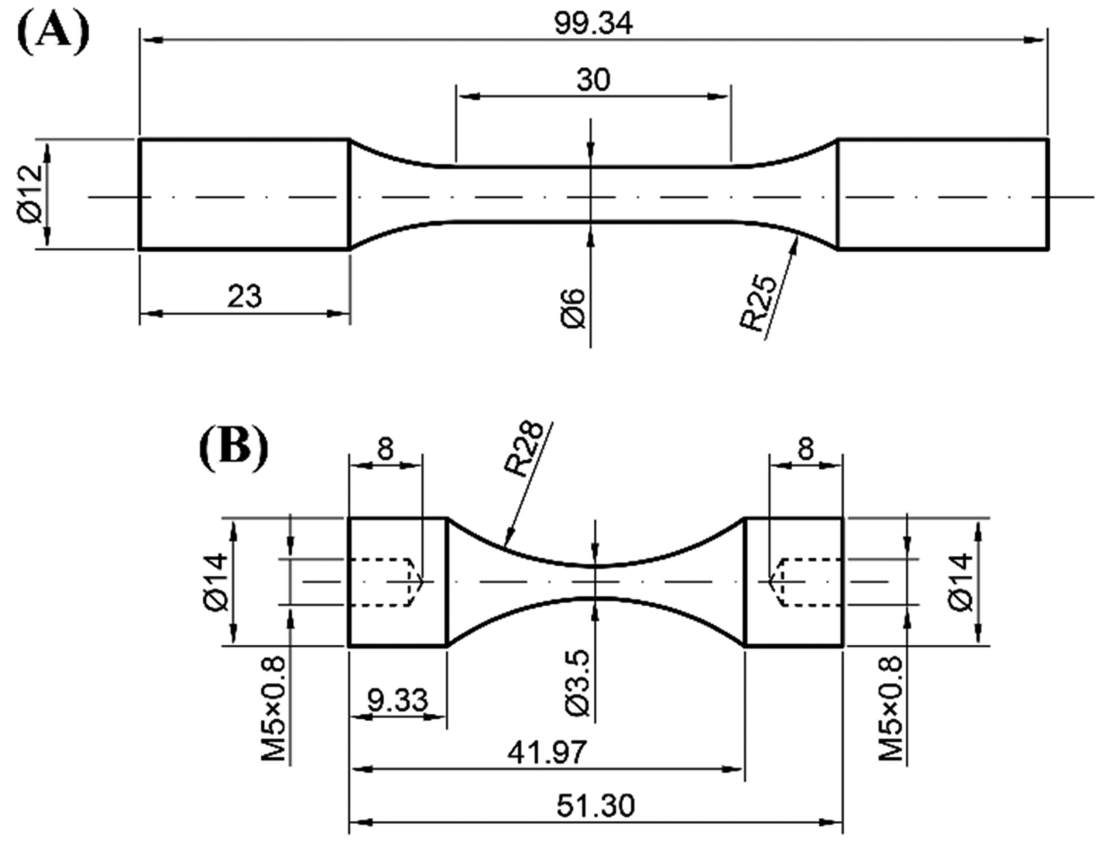

F I G URE 2 Shape and dimensions ( $\mathrm{mm}$ ) of tested specimens: (A) for tensile tests, and (B) for ultrasonic fatigue tests 


\section{3 | RESULTS AND DISCUSSION}

\section{1 | Effects of processing parameters on resulted porosity}

The results of the measured porosity $R_{\mathrm{D}}$ for the nine groups of specimens are listed in Table 2. According to the extremum difference analysis, ${ }^{34}$ the value of the extremum difference can reflect the influence of each factor on the porosity, that is, the larger the extremum difference, the more remarkable the influence significance of a factor. The values of extremum difference for each concerned factor are obtained as $3.87 \%$ for laser power, $2.38 \%$ for layer thickness, $0.78 \%$ for scan speed and $3.00 \%$ for hatch spacing. Therefore, the influence of the four factors on the porosity $R_{\mathrm{D}}$ in sequence is laser power $>$ hatch spacing $>$ layer thickness $>$ scan speed. The laser power is the most significant factor in controlling the resulted porosity, whereas the scan speed has little effect.

Figure 3 shows the variation of resulted porosity of the nine experimental groups with the change of the concerned processing parameters of laser power, layer thickness, scan speed and hatch spacing.

It is seen from Figure 3 that the porosity decreases with the increasing of laser power and it arrives at the lowest value when laser power is $160 \mathrm{~W}$, that is, the porosity decreases from $5.35 \%$ to $1.48 \%$ as the laser power increases from 120 to $160 \mathrm{~W}$. Then, it increases to $2.18 \%$ with an increase of laser power to $200 \mathrm{~W}$. Normally, greater laser power will bring about stronger energy, and the resulted porosities among solids will be filled under surface tension and capillary force ${ }^{10}$ However, when the laser power exceeds a certain value, the increased input heat may gasify some powders, which may result in a higher porosity.

Figure 3 shows that the value of porosity is of an ascending trend as the increase of layer thickness from 30 to $60 \mu \mathrm{m}$ with the total increment of $2.38 \%$. The increase rate of porosity is much faster for the layer thickness from 30 to $45 \mu \mathrm{m}$ than that from 45 to $60 \mu \mathrm{m}$. This means that the rising of powder thickness will lead to the unexpected enhancement of nodulizing tendency and uneven melting.

It is interesting that the change of scan speed from 800 to $1200 \mathrm{~mm} \mathrm{~s}^{-1}$ just has a little effect on the variation of resulted porosity as shown in Figure 3. The porosity decreases from $3.33 \%$ to $2.55 \%$ as the scan speed decreases from 1200 to $1000 \mathrm{~mm} \mathrm{~s}^{-1}$, and it then increases to $3.13 \%$ as the scan speed further decreases to $800 \mathrm{~mm} \mathrm{~s}^{-1}$. When the scan speed reduces to a certain value, the excessive energy input will be generated, which will cause a higher porosity.

Figure 3 also shows that the value of porosity increases sharply with the increase of hatch spacing from 0.07 to $0.13 \mathrm{~mm}$ with the total range of $3.00 \%$. The condition of small hatch spacing will increase the overlapping area of adjacent scanning lines, which may generate the overlying of laser beam energy. Thus, the uniform distribution of energy will make the powder between scanning lines melt completely, and the depth of melting lines will tend to be evenly arranged. As a result, the subsequent melting liquid grows on the solidified scanning lines and substrate (i.e., solidified layer). In this way, each scanning line proceeds stably from liquid to solid.

Above all, it can be anticipated from the results of Figure 3 that the optimal combination of the four processing parameters is laser power $160 \mathrm{~W}$, layer
FIGURE 3 Variation of resulted porosity with processing parameters of laser power $(P)$, layer thickness $(t)$, scan speed $(v)$ and hatch spacing $(h)$ [Colour figure can be viewed at wileyonlinelibrary.com]

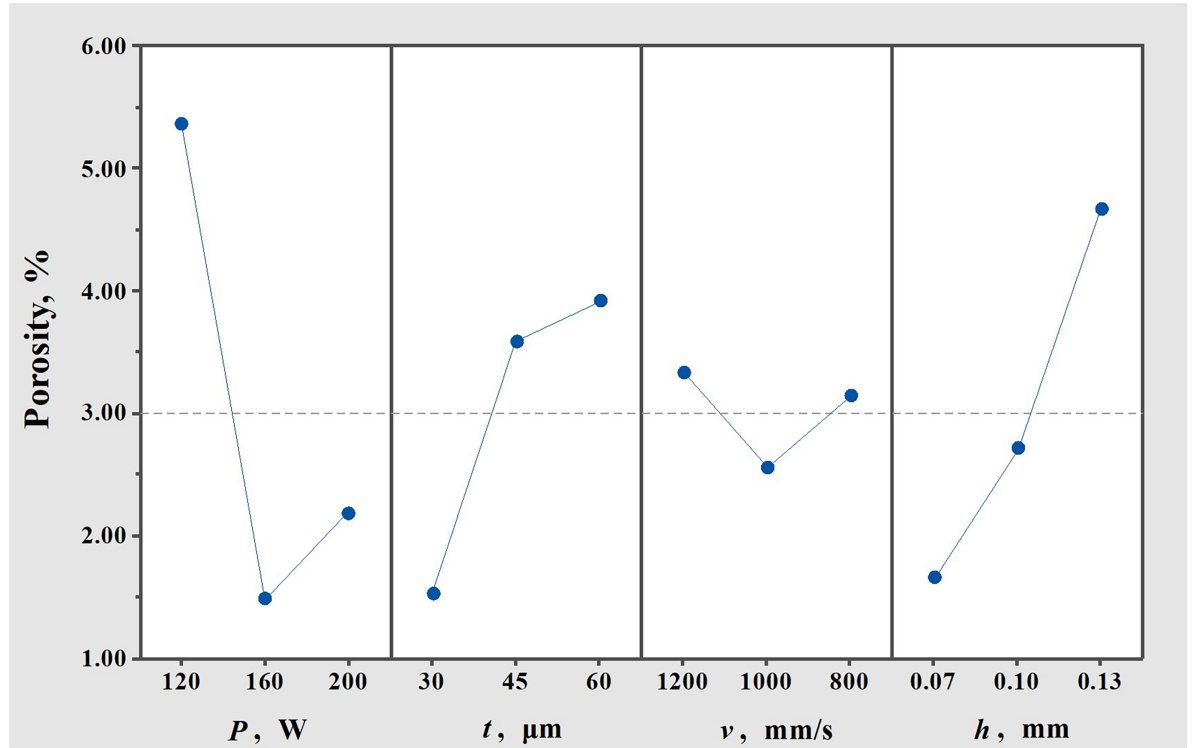


thickness $30 \mu \mathrm{m}$, scan speed $1000 \mathrm{~mm} \mathrm{~s}^{-1}$ and hatch spacing $0.07 \mathrm{~mm}$. For this combination, the volumetric energy density $E$ is readily calculated by Equation 1 as $76.2 \mathrm{~J} \mathrm{~mm}^{-3}$.

Table 3 gives the results of the ANOVA by Equations $2-5$. Here, $F$ is the $f$-distribution in mathematic statistics. ${ }^{33}$ In the present analysis, $F$ is used to evaluate the significance of each factor versus porosity, which was computed and compared with a critical value. ${ }^{33} D F$ is the degree of freedom, which is the number of the assigned

T A B LE 3 Results of analysis of variance (ANOVA) due to obtained porosity

\begin{tabular}{|llllll|} 
Factor & $\boldsymbol{S S}$ & $\boldsymbol{D F}$ & $\boldsymbol{M S}$ & $\boldsymbol{F}$ & $\boldsymbol{S I G}$ \\
\hline$P$ & 76.91 & 2 & 38.45 & 74.62 & 0.000 \\
\hline$t$ & 29.91 & 2 & 14.96 & 29.05 & 0.000 \\
\hline$v$ & 2.90 & 2 & 1.45 & 2.82 & 0.086 \\
\hline$h$ & 41.78 & 2 & 20.89 & 40.56 & 0.000 \\
\hline Error & 9.27 & 18 & 0.515 & & \\
\hline Total & 160.8 & 26 & & & \\
\hline
\end{tabular}

levels minus 1 for a factor. $S S$ is the sum of squares in relation to a factor, which was calculated by Equation 3 . $M S$ is the mean square of a factor, which is the sum of square divided by the related degree of freedom. The sum of squares of the errors correlated to all factors was calculated by Equation 5, and the value is 9.27 as shown in Table 3. In fact, the value of $F$ is the ratio of a given $M S$ to its error in Table 3. The critical value of $F$ for $95 \%$ confidence level, that is, significance level of $\alpha=0.05$, can be obtained as $F_{0.05,2,18}=3.55$, which is referred to Mao et al. ${ }^{35}$ Here, the subscript 2 corresponds to the degree of freedom for each factor, and the subscript 18 corresponds to the total degrees of freedom for the errors. Commonly, when $F$ is larger than the critical value, that is, $F>3.55$, the related factor or design parameter is of a significant effect on the target. Otherwise, the factor is insignificant and can be neglected. Therefore, the changes of factors $P$ (laser power), $t$ (layer thickness) and $h$ (hatch spacing) have significant effects on porosity because the related $F$ value is greater than 3.55 , whereas $v$ (scan speed) has no significant effect on porosity. Among all these factors,

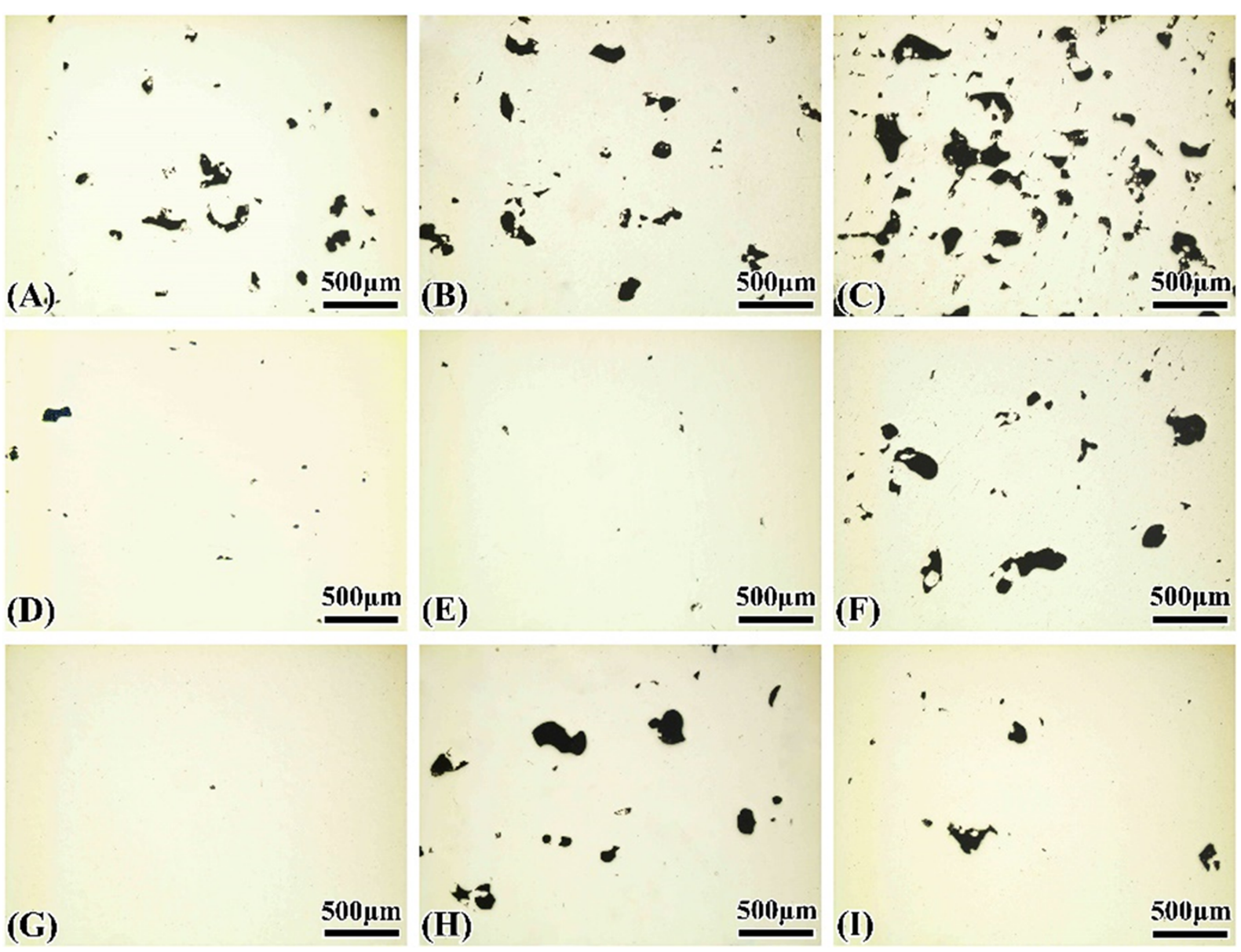

F I G U RE 4 Optical microscopy images showing defect distribution of nine group specimens in horizontal cross section: (A) Group 1, (B) Group 2, (C) Group 3, (D) Group 4, (E) Group 5, (F) Group 6, (G) Group 7, (H) Group 8 and (I) Group 9 [Colour figure can be viewed at wileyonlinelibrary.com] 
laser power is the most significant one with the largest $F$ value of 74.6, which can be ascribed to the influence of laser power on the energy input. In addition, the significance value $(S I G)$ in Table 3 is calculated by SPSS software with the given $F$ value and the degree of freedom. In ANOVA, SIG indicates the significance level of the concerned factor. There is a stipulation that if the value of $S I G$ is less than 0.05 , the related factor is statistically significant, and if $S I G$ is less than 0.01 , the related factor is highly significant. ${ }^{33}$ Otherwise, the related factor is insignificant. By the indication of the $S I G$ values shown in Table 3, it is evident that the factors of laser power, layer thickness and hatch spacing are highly significant in the effect on the porosity of the SLM parts, whereas the scan speed with the $S I G$ value of 0.086 shows an insignificant effect on the resulted porosity.

For the validation of the optimal combination of processing parameters, a validation group of specimens, that is, Group 10, were accordingly manufactured by the same SLM equipment with the processing parameters and the resulted porosity shown in Table 2 . The porosity of Group 10 is $0.20 \pm 0.05 \%$, which is even much lower than the best value of $0.53 \pm 0.15 \%$ for Group 7 in the OED series.

In addition to the density measurements showing the porosity of the nine group specimens in OED produced by SLM, which provides a general and quantitative characterization of the defect status of the specimens, the morphology of defects for the specimens were also systemically examined in both horizontal and longitudinal cross sections with $\mathrm{OM}$, and the observations are shown in Figures 4 and 5. It is seen that Figures $4 \mathrm{G}$ and $5 \mathrm{G}$ of Group 7 are the cleanest images containing almost no defects, which is the specimen group with the lowest porosity value of $0.53 \%$. The images of Figures $4 \mathrm{C}$ and $5 \mathrm{C}$ of Group 3 contain the largest amount of defects, which is the specimen group with the largest porosity value of $8.03 \%$. The images of Figures $4 \mathrm{~B}$ and 5B for Group 2 with the porosity value of $5.18 \%$ and those of Figures $4 \mathrm{H}$ and $5 \mathrm{H}$ for Group 8 with the porosity value of $4.73 \%$ also contain a large amount of defects. Then, the amount of defects gradually reduces from Figures $4 \mathrm{~A}$ and $5 \mathrm{~A}$ to $4 \mathrm{~F}$
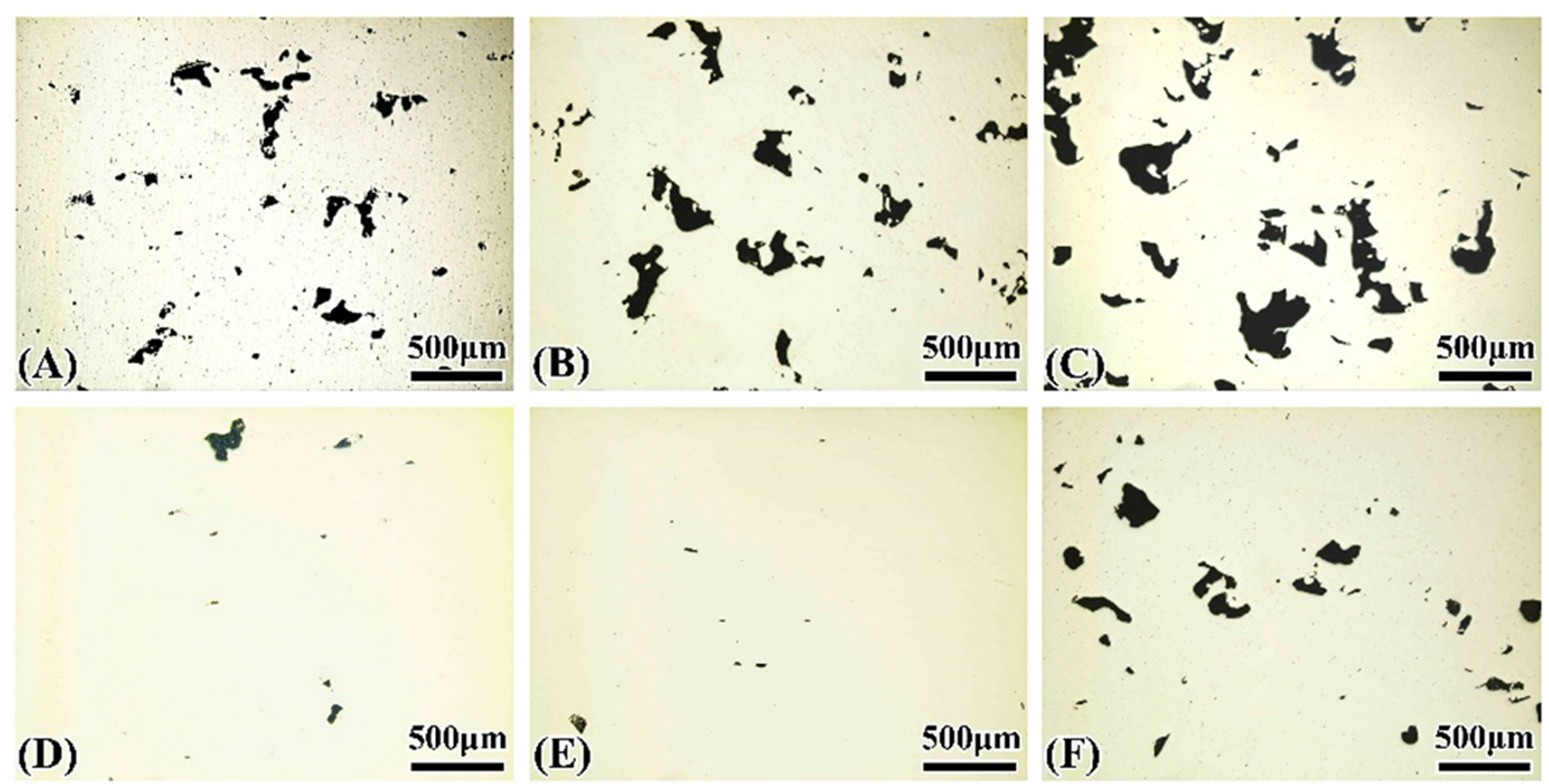

(D)

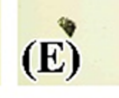

(F)
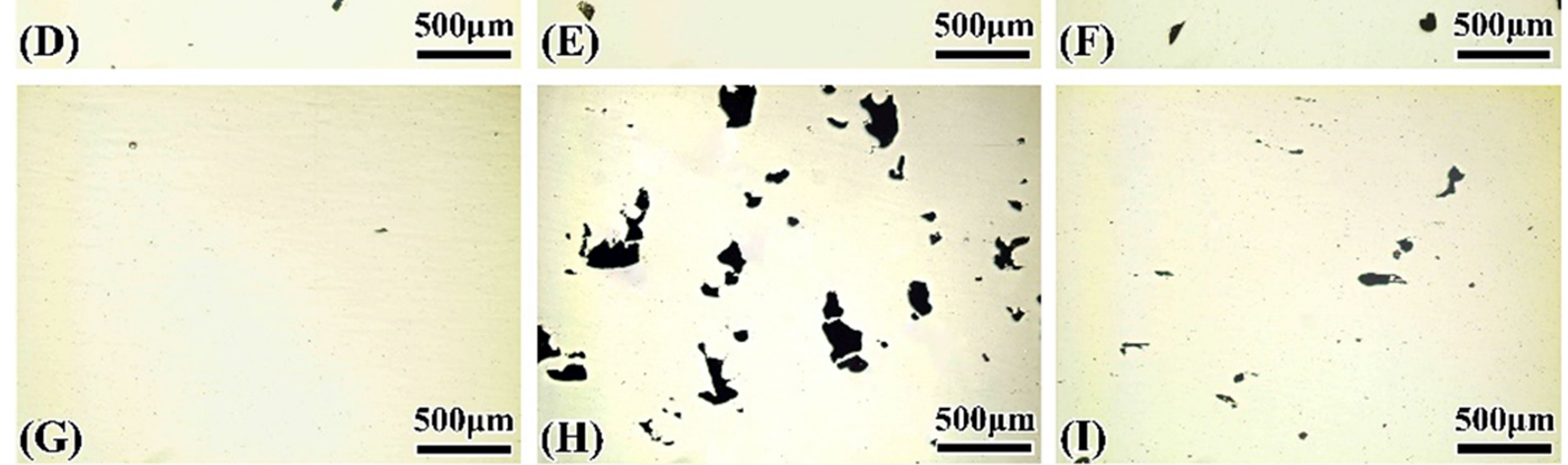

F I G U RE 5 Optical microscopy images showing defect distribution of nine group specimens in longitudinal cross section: (A) Group 1, (B) Group 2, (C) Group 3, (D) Group 4, (E) Group 5, (F) Group 6, (G) Group 7, (H) Group 8 and (I) Group 9 [Colour figure can be viewed at wileyonlinelibrary.com] 
and $5 \mathrm{~F}$, in correspondence to Groups $1\left(R_{\mathrm{D}}=2.85 \%\right)$ and $6\left(R_{\mathrm{D}}=2.40 \%\right)$. Thereafter, the images of Figures $4 \mathrm{I}$ and 5I for Group $9\left(R_{\mathrm{D}}=1.28 \%\right)$, Figures $4 \mathrm{D}$ and $5 \mathrm{D}$ for Group $4\left(R_{\mathrm{D}}=1.20 \%\right)$ and Figures $4 \mathrm{E}$ and 5E for Group $5\left(R_{\mathrm{D}}=0.83 \%\right)$ contain decreasing amount of defects. Finally, the images of Figures $4 \mathrm{G}$ and $5 \mathrm{G}$ for Group 7 contain almost no defects.

The defects of Groups 1 (Figures $4 \mathrm{~A}$ and $5 \mathrm{~A}$ ), 2 (Figures 4B and 5B), 3 (Figures 4C and 5C), 6 (Figures 4F and $5 \mathrm{~F}$ ) and 8 (Figures $4 \mathrm{H}$ and $5 \mathrm{H}$ ) are of irregular shape in both horizontal and longitudinal directions. These irregular defects are lack-of-fusion domains due to insufficient energy input. Some are distributed in relation with the scanning direction or layer direction, which are the indications of insufficient melting in track-track or layer-layer overlapping. The amount of defects decreases substantially in Groups 5 (Figures $4 \mathrm{E}$ and $5 \mathrm{E}$ ) and 7 (Figures 4G and 5G). Defects in such groups are small and almost equiaxed.

For both the horizontal and longitudinal sections of each specimen group, 15 images, each with the same size as an image in Figures 4 and 5, were examined and the defect fraction for each group in both sections was measured respectively, by using Image-Pro Plus 6.0 software. The results of defect fraction measurements for the 10 specimen groups (nine OED groups plus validation group) together with the obtained values of $R_{\mathrm{D}}$ are presented in Figure 6, showing that the results of defect fraction are generally consistent with the obtained $R_{\mathrm{D}}$ values. It is seen from Figure $6 \mathrm{~A}$ that for the groups with low porosity such as Groups 4, 5, 7 and 10, the defect fraction of horizontal cross section is almost identical to that of longitudinal cross section and the result is close or slightly lower than the related value of $R_{\mathrm{D}}$, which is due to the fact that some small size defects cannot be detected in the OM measurement, whereas for the groups with high porosity, such as Groups 2, 3 and 8, the result of defect fraction is higher than the related $R_{\mathrm{D}}$ value, which is partially due to the fact that the large defects of lack-of-fusion may contain unmelted powder particles that cannot be identified as defects in the $R_{\mathrm{D}}$ measurement by Archimedes method. Nevertheless, such a difference is marginal and will not alter the general trend of the effect of $R_{\mathrm{D}}$ on the tensile and fatigue behaviour of the SLMed specimens. Note also that the defect fraction of longitudinal direction is higher than that of horizontal direction for Groups 3 and 8. The relatively low energy input may induce insufficient molten pool depth, which can lead to a large number of lack-of-fusion defects between adjacent layers. This may cause the higher extent of porosity in longitudinal direction than horizontal direction.

Figure 6B shows the variation of detected porosity as a function of laser input energy density for the 10 specimen groups. Overall, the value of porosity or defect fraction decreases with the increasing of laser input energy density. It should be emphasized that when the energy density is between 65 and $85 \mathrm{~J} \mathrm{~mm}^{-3}$, the porosity or defect fraction of the SLMed specimens tends to a stably low level, which is an important and useful hint for the production of AM parts.

Here, it is worthwhile to address that the variation of porosity for the nine group specimens of the OED series shown in Table 2 is of little dependence on the processing parameter combinations. If the variation or standard deviation of the porosity is considered as a factor for the analysis, more data of the porosity for specimen groups should be measured. Indeed, this is an interesting issue and needs further in-depth investigation.
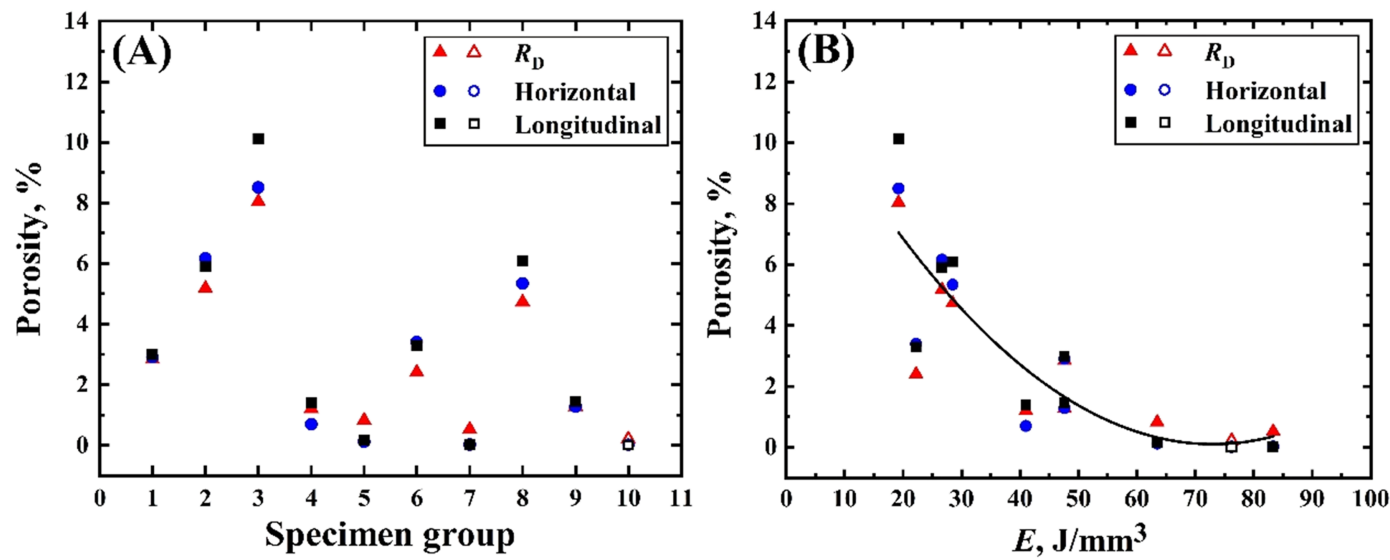

F I G URE 6 (A) Porosity percentage of 10 group specimens and (B) porosity percentage as a function of volumetric energy density $E$; solid symbols indicating the cases of orthogonal experiment design (OED) groups (Groups 1-9); hollow symbols indicating the cases of validation group (Group 10) [Colour figure can be viewed at wileyonlinelibrary.com] 


\subsection{Effects of processing parameters on tensile properties}

For each processing parameter set, that is, each experimental group, four specimens were tested in monotonic tension. The average values of yield strength $\left(\sigma_{\mathrm{y}}\right)$, ultimate tensile strength $\left(\sigma_{\mathrm{u}}\right)$ and total elongation $\left(\varepsilon_{\mathrm{t}}\right)$ are also shown in Table 2 and illustrated in Figure 7. The large scattering of tensile properties shown in Table 2 is very likely to be caused by the porosity or defects contained by the specimens produced by SLM. Also, the effect of porosity or defects on the total elongation is more remarkable than on the yield and ultimate strength, because the response of ductility is more sensitive to the existence of defects.

Here, Figure 7A shows the tensile properties as a function of the porosity of the 10 group specimens, illustrating the variation of the tensile properties with the combination of processing parameters. The values of ultimate tensile strength of all 10 groups, except Group 3 with the largest $R_{\mathrm{D}}$ value of $8.03 \%$, are located in the range from 1000 to $1228 \mathrm{MPa}$, which agrees well with the results ranging from 1006 to $1327 \mathrm{MPa}$ reported in the literature. ${ }^{36}$ For the nine groups of OED series, although there is less pronounced decrease in tensile strength as the porosity increases except Group 3, the elongation is significantly reduced from $2.8 \%$ to $0.8 \%$ as the increase of the porosity from $0.53 \%$ to $8.03 \%$. Even for the best case of Group 7, the value of elongation is only $2.4 \%$, which is in the lower end of the elongation range from $1.6 \%$ to $11.9 \%$ of the Ti-6Al-4V parts manufactured by powder bed fusion. ${ }^{36}$ The low ductility of the present specimens is the reflection of their possessed microstructure, which should be further investigated. The validation group (Group 10$)$ with the lowest porosity $(0.20 \%)$ has the elongation of $4 \%$, which is much higher than the best value of $2.8 \%$ for Group 5 in the OED series.
Figure 7B shows the relation between the tensile properties and the input energy density of the 10 group specimens. Both the yield strength and ultimate tensile strength increase with the energy density. However, there is a descending trend of tensile strength when the energy density is beyond $65 \mathrm{~J} \mathrm{~mm}^{-3}$. Moreover, the value of elongation is markedly affected by laser input energy density, and it reaches the highest value when the energy density is at $76.2 \mathrm{~J} \mathrm{~mm}^{-3}$ for the validation group. Thus, it seems that the best optimal energy density range with regard to tensile properties is between 65 and $80 \mathrm{~J} \mathrm{~mm}^{-3}$.

\subsection{Effects of processing parameters on $S-N$ data}

Figure 8 presents the obtained $S$ - $N$ data for the 10 groups of specimens in terms of stress amplitude versus fatigue life $N_{\mathrm{f}}$. It is seen that the $S-N$ data for the 10 groups vary greatly. The cycles to fatigue failure are between $10^{5}$ and $10^{9}$ for all specimens, which cover the HCF and VHCF regimes. A sharp decrease in fatigue strength occurred when the porosity of the specimens becomes larger. This implies that the porosity has a significant effect on the HCF and VHCF behaviour of the SLMed Ti-6Al-4V alloy.

For the nine groups of the OED series, it is seen from Figure $8 \mathrm{~A}$ that Group 3 with the highest $R_{\mathrm{D}}$ value $(8.03 \%)$ possesses the lowest fatigue strength at $10^{7}$ failure cycles of about $90 \mathrm{MPa}$, whereas for the specimens with the lowest porosity (Group 7, $R_{\mathrm{D}}=0.53 \%$ ), the fatigue strength at $10^{7}$ failure cycles has the highest value of about $270 \mathrm{MPa}$. The fatigue performances of the rest seven groups are distributed in between the data band defined by Groups 3 and 7 as shown in Figure 8A. For the validation group (Group $10)$, which has the even lower porosity $\left(R_{\mathrm{D}}=0.20 \%\right)$ than that of Group 7, the fatigue strength at $10^{7}$ failure cycles has a higher value (300 MPa) than that of Group 7.
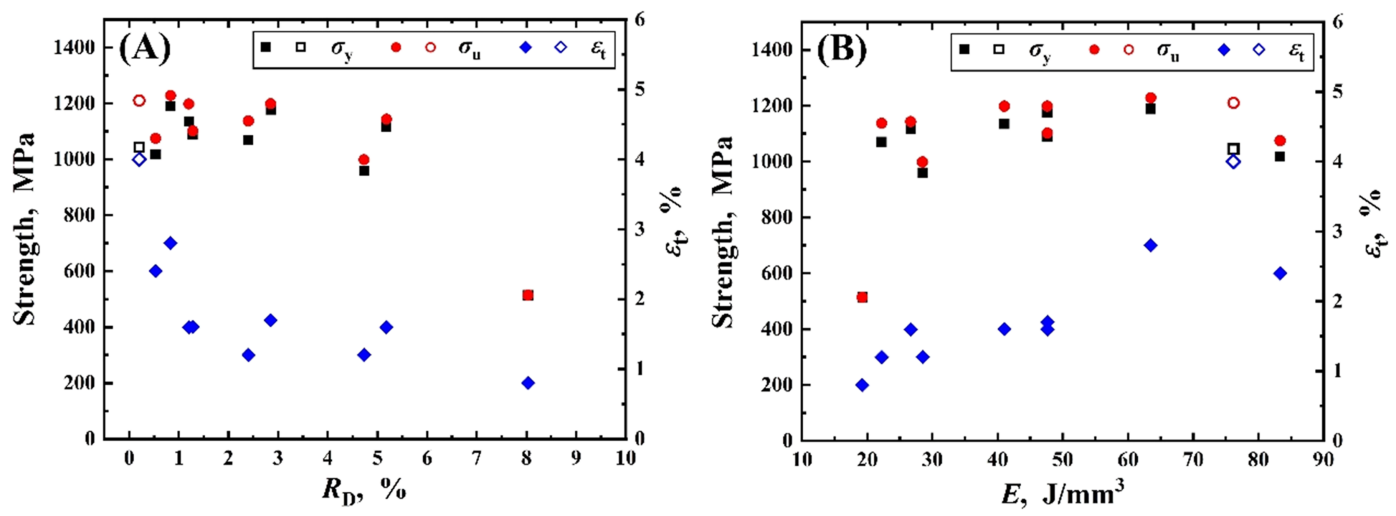

F I G U RE 7 Variation of tensile properties with (A) $R_{\mathrm{D}}$ and (B) volumetric energy density $E$; solid symbols indicating the cases of orthogonal experiment design (OED) groups (Groups 1-9); hollow symbols indicating the cases of validation group (Group 10) [Colour figure can be viewed at wileyonlinelibrary.com] 

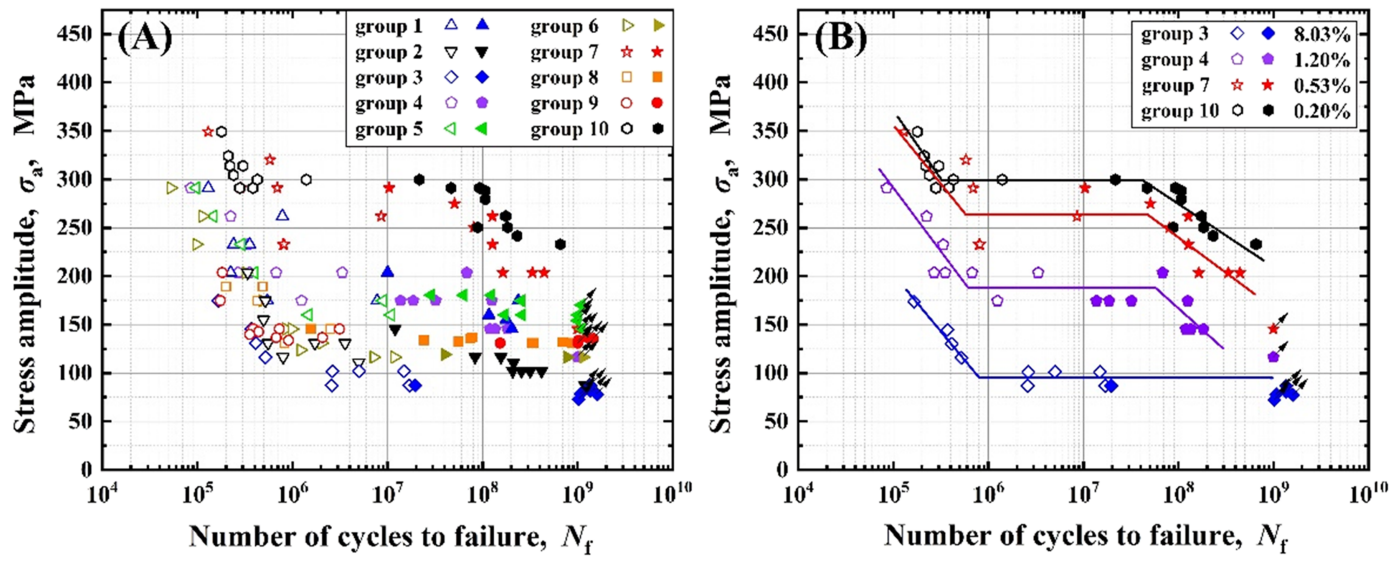

F I G U RE 8 (A) $S$ - $N$ data of 10 group specimens in terms of stress amplitude versus number of cycles to failure and (B) $S$ - $N$ curves of Groups 3, 4, 7 and 10; hollow symbols indicating surface crack initiation, solid symbols indicating internal (subsurface) crack initiation and symbols with arrow indicating run-out specimens; Group 10 being the validation test [Colour figure can be viewed at wileyonlinelibrary.com]

For the sake of clear expression, Figure 8B shows the $S-N$ data of Groups 3, 4, 7 and 10, which are the best (Group 10), the worse (Group 3) and two middle ones (Groups 4 and 7). It is seen that the best fatigue strength at $10^{7}$ cycles (Group 10, $300 \mathrm{MPa}$ ) is more than three folds of the worse fatigue strength at $10^{7}$ cycles (Group 3, $90 \mathrm{MPa}$ ). For Group 4 with the porosity of $1.2 \%$ and Group 7 with the porosity of $0.53 \%$, the values of fatigue strength at $10^{7}$ cycles are about 180 and $270 \mathrm{MPa}$, respectively.

It is seen from Figure 8B that there are two types of $S-N$ curve trends, which is correlated to the porosity of the related groups. The $S-N$ curves for Groups 4,7 and 10 exhibit a step-wise trend, and there is no fatigue limit up to $10^{9}$ loading cycles. The $S$ - $N$ curve for Group 3 (the worse group, $R_{\mathrm{D}}=8.03 \%$ ) is a 'single-wise' trend, namely, linearly decreasing and tending to a horizontal level at $10^{6}$ failure cycles, implying the existence of a fatigue limit. The different trends of $S$ - $N$ curves can be ascribed to the difference of the size, the shape and the distribution of porosity or defects contained by the SLMed specimens. On the one hand for the case of high porosity, the specimens contain a large amount of defects and have high possibility of containing large size defects. The fatigue strength or applied cyclic stress first decreases with the increase of the fatigue life. When the stress is reduced to a certain level, the fatigue crack initiation and growth will be more dominant by the defects with different sizes, and the fatigue life presents a large scattering. In other words, at a certain low stress level, the fatigue failure may happen at a relatively short life due to the defects with a large size, and also may happen at a long life due to the defects with a small size. On the other hand for the case of low porosity, the stepwise or duplex $S$ - $N$ curves present similar to the VHCF cases of high-strength steels, which is resulted from the surface crack initiation and internal crack initiation thus to form the step-wise or duplex trend. The in-depth
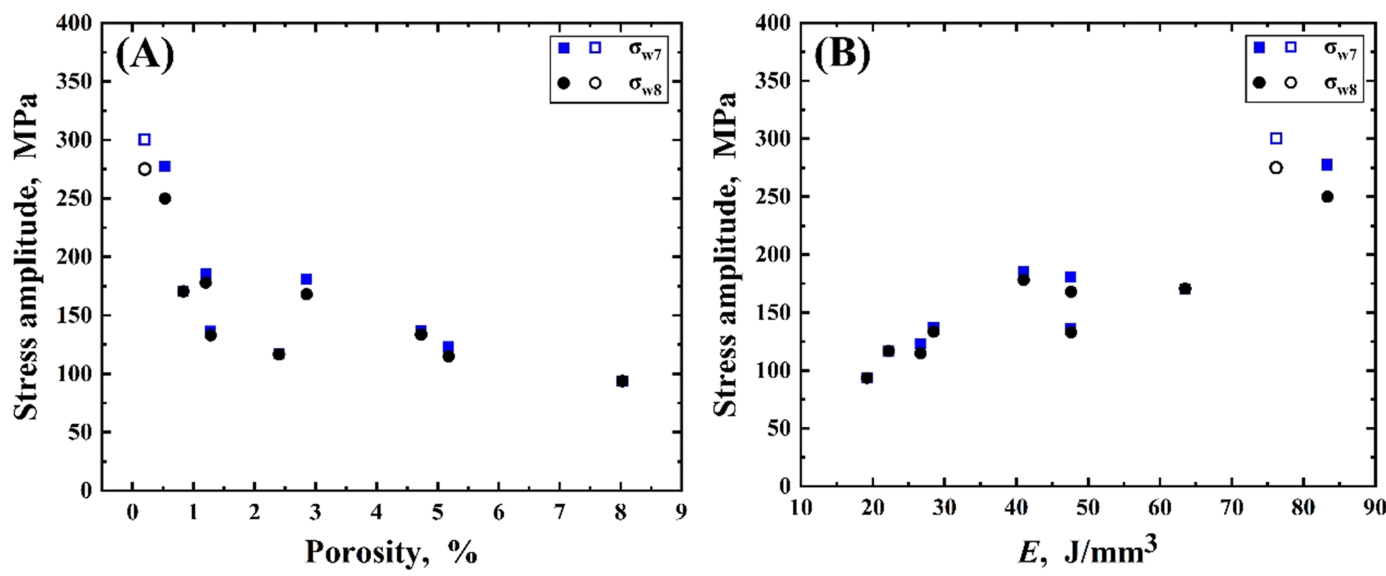

F I G U RE 9 Fatigue strength at $10^{7}\left(\sigma_{\mathrm{w} 7}\right)$ and $10^{8}\left(\sigma_{\mathrm{w} 8}\right)$ cycles as a function of (A) porosity $R_{\mathrm{D}}$ and (B) energy density $E$; solid symbols indicating the porosity of OED experiment; hollow symbols indicating the fatigue strength of validation experiment [Colour figure can be viewed at wileyonlinelibrary.com] 
mechanism of such two types of $S-N$ curve trends needs to be further analysed.

Figure $8 \mathrm{~A}$ as well as $8 \mathrm{~B}$ also contains the information of fatigue crack initiation mode. It is seen that surface crack initiation appears for all fatigue failures roughly before $10^{7}$ cycles, that is, within HCF regime, whereas internal crack initiation prevails for the fatigue failures roughly beyond $10^{7}$ cycles, that is, within VHCF regime. The characteristics of fatigue crack initiation and early growth will be specifically discussed in the next subsection.

The fatigue strength at $10^{7}$ and $10^{8}$ cycles for 10 groups of specimens as a function of porosity and energy density is illustrated in Figure 9A,B, respectively. It is seen that the fatigue strength gradually decreases as the porosity increases (Figure 9A), and the fatigue strength gradually increases as the energy density increases (Figure 9B). However, the fatigue strength is somewhat lowered when the energy density from 76.2 to $83.3 \mathrm{~J} \mathrm{~mm}^{-3}$. It is evident that in comparison with the tensile properties, the fatigue strength is more sensitive to the variation of the porosity or energy density.

\section{4 | SEM observations and analyses}

The fracture surfaces of fatigue failed specimens were examined by SEM. In most cases of conventional casting produced Ti-6Al-4V with bimodal ${ }^{37}$ or equiaxed microstructure, ${ }^{38}$ the fatigue crack initiation in HCF and VHCF under $R=-1$ is from the surface of specimen, but in some rare cases, ${ }^{39}$ crack initiation in VHCF regime may from the interior of specimen. In the present investigation of all group specimens made by SLM, the fatigue crack initiation is almost from the surface of specimen between $10^{5}$ and $10^{7}$ cycles and is almost from the interior of specimen between $10^{7}$ and $10^{9}$ cycles. The crack origins are due to the existed defects induced during the SLM process, even for the cases of surface crack initiation, except for very few cases of surface crack initiation without a defect in the origin. The SEM images shown in Figure 10 are four examples of surface crack initiation, for which the specimens are all failed in HCF regime. Figure 10A shows the surface crack initiation morphology of a failed specimen from Group 7 that contains the lowest porosity in the OED series. Note that no preexisted defect is observed in the crack origin site of Figure $10 \mathrm{~A}$ and the initiation is probably due to the localized deformation at the surface. The cases similar to Figure 10A are very rare, that is, only very few failures of surface crack initiation happen without the participation of pre-existed defects. This is due to the fact that a large number of defects resulted from lack-of-fusion exist in the SLMed specimens. Figure 10B shows a morphology of surface crack initiation with a defect as the origin from Group $5\left(R_{\mathrm{D}}=0.83 \%\right)$, which happens in most cases of surface crack initiation. Figure $10 \mathrm{C}$ is another
F I G U RE 10 Scanning electron microscopy (SEM) images showing fracture surface morphologies of the specimens failed in high-cycle fatigue (HCF) regime with surface crack initiation: (A) Group 7, $\sigma_{\mathrm{a}}=291 \mathrm{MPa}$ and $N_{\mathrm{f}}=6.95 \times 10^{5}$; (B) Group $5, \sigma_{\mathrm{a}}=175 \mathrm{MPa}$ and $N_{\mathrm{f}}=8.93 \times 10^{6}$; (C) Group 4, $\sigma_{\mathrm{a}}=203 \mathrm{MPa}$ and $N_{\mathrm{f}}=6.75 \times 10^{5}$ and (D) Group $4, \sigma_{\mathrm{a}}=291 \mathrm{MPa}$ and $N_{\mathrm{f}}=8.52 \times 10^{4}$; arrows in micrographs pointing at crack initiation site
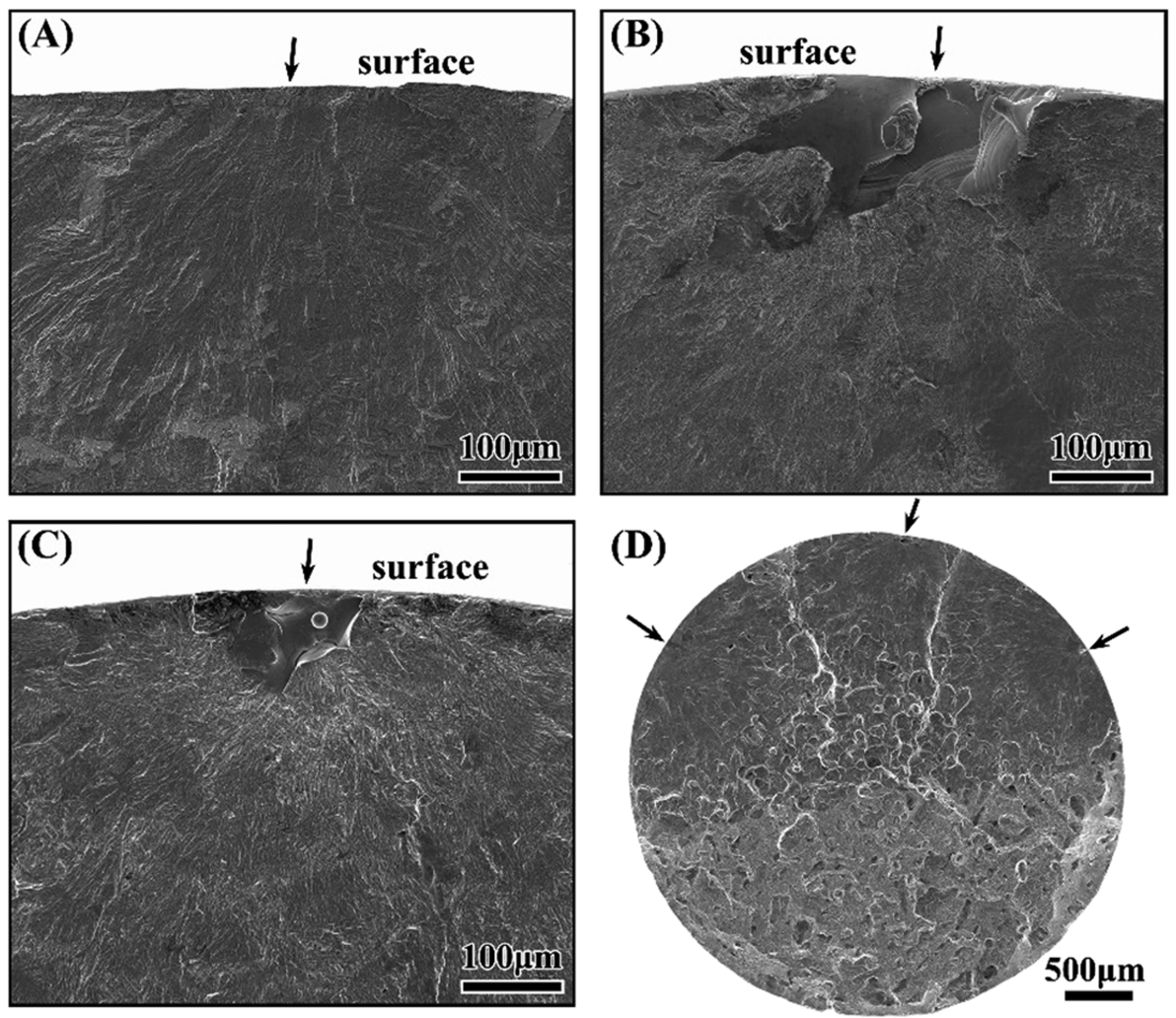
typical image of surface crack initiation from Group $4\left(R_{\mathrm{D}}=1.20 \%\right)$, showing that crack origin site is again a lack-of-fusion defect. From Figure 10B,C, it is seen that some defects of lack-of-fusion can located just at the surface area of specimen, which are the predominant sites for surface crack initiation in $\mathrm{HCF}$ regime. Apart from the single crack origin of Figure 10B,C, it is interesting that multiple origins in surface crack initiation may happen as shown in Figure 10D from Group $4\left(R_{\mathrm{D}}=1.20 \%\right)$, in which three crack origins are observed and all are in relation to the defects by SLM. Note that the multiple origin crack initiation occurs in the fatigue loading of relatively large cyclic stress and relatively low failure cycles. In other words, similar to Figure 10D failed in close to $10^{5}$ cycles, other specimens failed in about $10^{5}$ cycles all possess the morphology of surface crack initiation with multiple origins.

Figure 11A is an SEM image of a Group 2 specimen failed in VHCF regime, showing internal crack initiation from a large defect of lack-of-fusion. Within this defect, the scanning directions in the upper and lower layers can be identified and marked by the arrows in Figure 11A. The angle between the two arrow lines roughly corresponds to the rotation of $60^{\circ}$ between the two layers. It is also seen that the voids are distributed with irregular shape along and between the hatch lines. The process of SLM is scanning line by line and layer by layer, which is controlled by the combination of the applied processing parameters. Figure 11B schematically shows the hatch lines in two layers. If the molten material fails to wet the previous layer and/or hatch line, the gap between adjacent hatch lines especially between the two layers (square marked in the centre of Figure 11B) may induce a large defect of lack-of-fusion, which is resulted from an insufficient energy density and/or a large hatch spacing. Thus, less overlap or even no overlap may occur between hatch lines as shown in Figure 11A. Therefore, for the purpose of producing fully dense SLM parts, the value of hatch spacing should be accordingly reduced.

Besides the defects generated by a lack of melting pool overlap as addressed above and shown in Figure $11 \mathrm{~A}, \mathrm{~B}$, in the cases where an insufficient energy density or a large layer thickness is applied, the defects due to a lack of penetration depth may occur between the adjacent layers. The SEM images of Figure 11C,D are the both sides of the fracture surface for a specimen of Group $6\left(R_{\mathrm{D}}=2.40 \%\right)$ failed in VHCF regime, which is a typical example of subsurface crack initiation at the defect of a lack of penetration depth. In Figure 11C, the unmelted powder particles are marked by the arrows, which are caused by the lack of penetration depth and thereby become entrapped underneath the melting pool and embedded within a large defect. An inadequate melting pool owing to insufficient energy input can induce
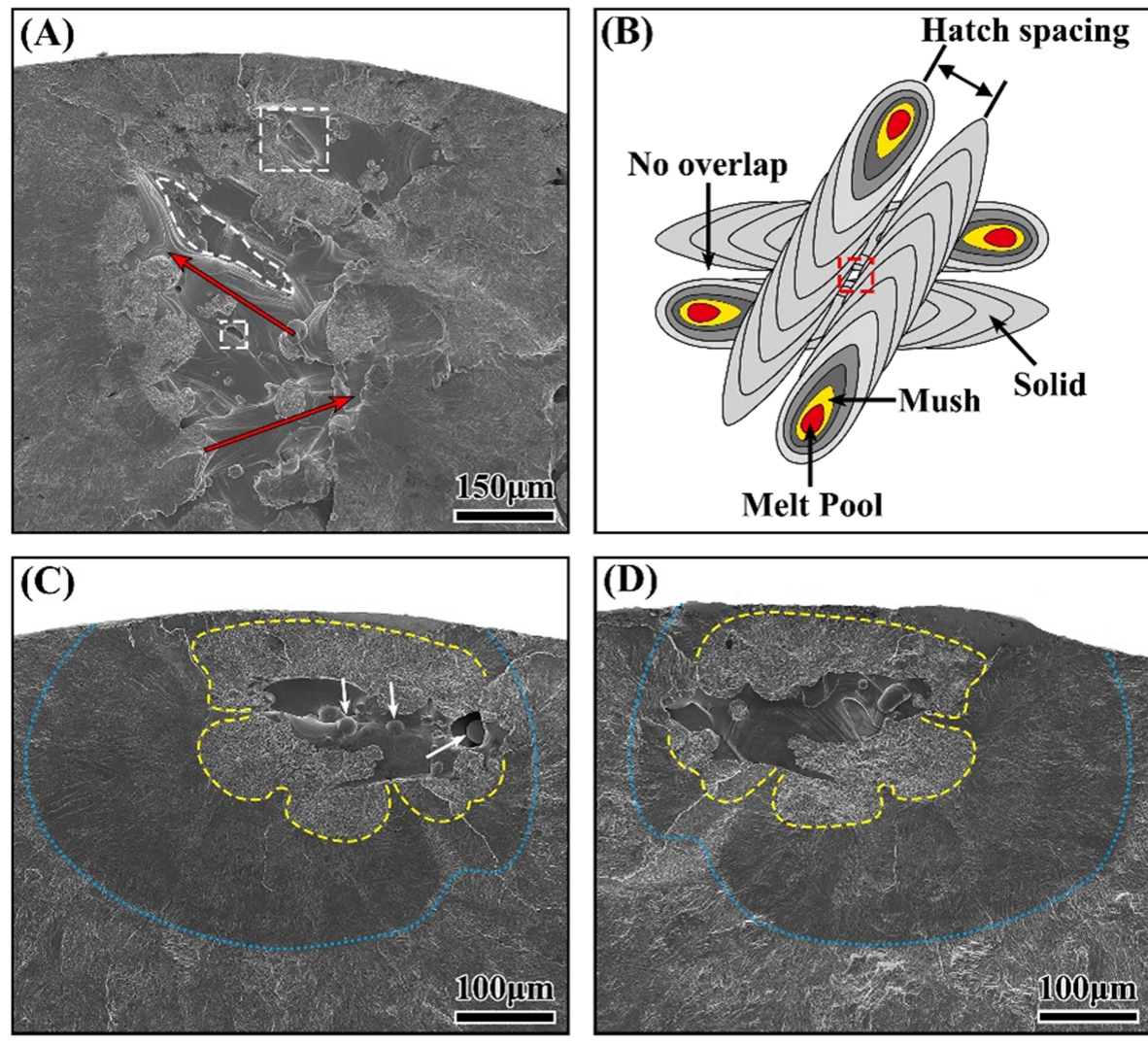

F I G U RE 11 (A) Typical fracture surface morphology of failed specimen due to less overlap between hatch lines (Group 2, $\sigma_{\mathrm{a}}=116 \mathrm{MPa}$ and $\left.N_{\mathrm{f}}=1.56 \times 10^{8}\right)$; (B) schematic of selective laser melting (SLM) melting pool without overlap; (C) typical fracture surface showing lack of penetration depth induced unmelted powder particles entrapped underneath the melting pool (Group 6, $\sigma_{\mathrm{a}}=116 \mathrm{MPa}$ and $\left.N_{\mathrm{f}}=7.88 \times 10^{8}\right)$ and (D) opposite fracture surface of $(\mathrm{C})$; dashed curve in (C) and (D) indicating RA region, dotted curve in (C) and (D) indicating FiE region and arrows in $(\mathrm{C})$ pointing at unmelted powder particles [Colour figure can be viewed at wileyonlinelibrary.com] 
above unmelted powder particles, even when the gap between hatch lines is well overlapped. This abnormal process may happen at different values of layer thickness if an insufficient energy input is applied.

Basically, Figure 11C,D clearly shows the morphology of crack initiation and early growth on both sides of the fracture surfaces with the feature of rough area (RA, marked with dashed curve) and fish-eye (FiE, marked with dotted curve). It is seen that the crack initiation region RA embraces the internal defect, which consumes most of the fatigue life and is the characteristic region of crack initiation in VHCF. ${ }^{40,41}$ Note also that the FiE pattern of crack early growth region formed outside the RA region is restricted by the specimen surface due to that the crack origin is located at the subsurface of the specimen.

Figure 12 presents the morphology of internal (subsurface) crack initiation for four groups of specimens. It is seen from the four SEM images that the shape as well as the size of the defect that caused the crack initiation varies. For Figure $12 \mathrm{~A}-\mathrm{C}$, the shape of defect is irregular and the size is relatively large, whereas for Figure $12 \mathrm{D}$, the defect is a nice ellipsoid and the size is relatively small. This phenomenon is ascribed to the difference in laser energy input. For the near-net-shaped AM parts like the specimens of the present investigation, the defects of lack-of-fusion or voids are more prone to be produced in the subsurface area due to the imperfect connection between the contour scanning and the matrix scanning.
Large defects with irregular shapes are more likely to prevail in this area when the laser energy input is insufficient. For Figure 12A-C with irregular shape defects, the specimens are Groups 1, 4 and 5, and the input energy density is $47.6,41.0$ and $63.5 \mathrm{~J} \mathrm{~mm}^{-3}$, respectively. But for Figure 12D of Group 7, the input energy density is increased to $83.3 \mathrm{~J} \mathrm{~mm}^{-3}$, in which the defects are possible to be with regular shape and small size. Again referred to Figure $8 \mathrm{~A}$, the fatigue performance in $\mathrm{HCF}$ and VHCF regimes for Groups 1, 4 and 5 are evidently deteriorative compared to that of Group 7. This result suggests that the laser input energy density is necessary to be beyond $63.5 \mathrm{~J} \mathrm{~mm}^{-3}$ to get a good quality of AM parts.

To further examine the characteristic region of internal crack initiation in VHCF regime, we select a fracture surface of a Group 7 specimen as shown in Figure 13. It is seen that the surface of RA region is a rough morphology containing crashed pieces of the microstructure as shown in Figure 13C. This feature is gradually diminishing along the direction away from the crack origin and the morphology is getting to be ridge-like feature as shown in Figure 13D, which is called quasicleavage of fatigue crack propagation. In other words, the microstructure refinement is more remarkable in the area close to the crack origin, and this process is gradually lessening in the location away from the crack origin, which can be explained by the mechanism of numerous cyclic pressing. ${ }^{40,41}$
F I G U RE 12 Typical fracture surface morphologies of failed specimens with subsurface/internal crack initiation: (A) Group

$1, \sigma_{\mathrm{a}}=174 \mathrm{MPa}$ and $N_{\mathrm{f}}=2.38 \times 10^{8}$;

(B) Group $4, \sigma_{\mathrm{a}}=174 \mathrm{MPa}$ and

$N_{\mathrm{f}}=1.87 \times 10^{7} ;$ (C) Group

$5, \sigma_{\mathrm{a}}=160 \mathrm{MPa}$ and $N_{\mathrm{f}}=1.71 \times 10^{8}$ and

(D) Group 7, $\sigma_{\mathrm{a}}=262 \mathrm{MPa}$ and

$N_{\mathrm{f}}=1.28 \times 10^{8}$
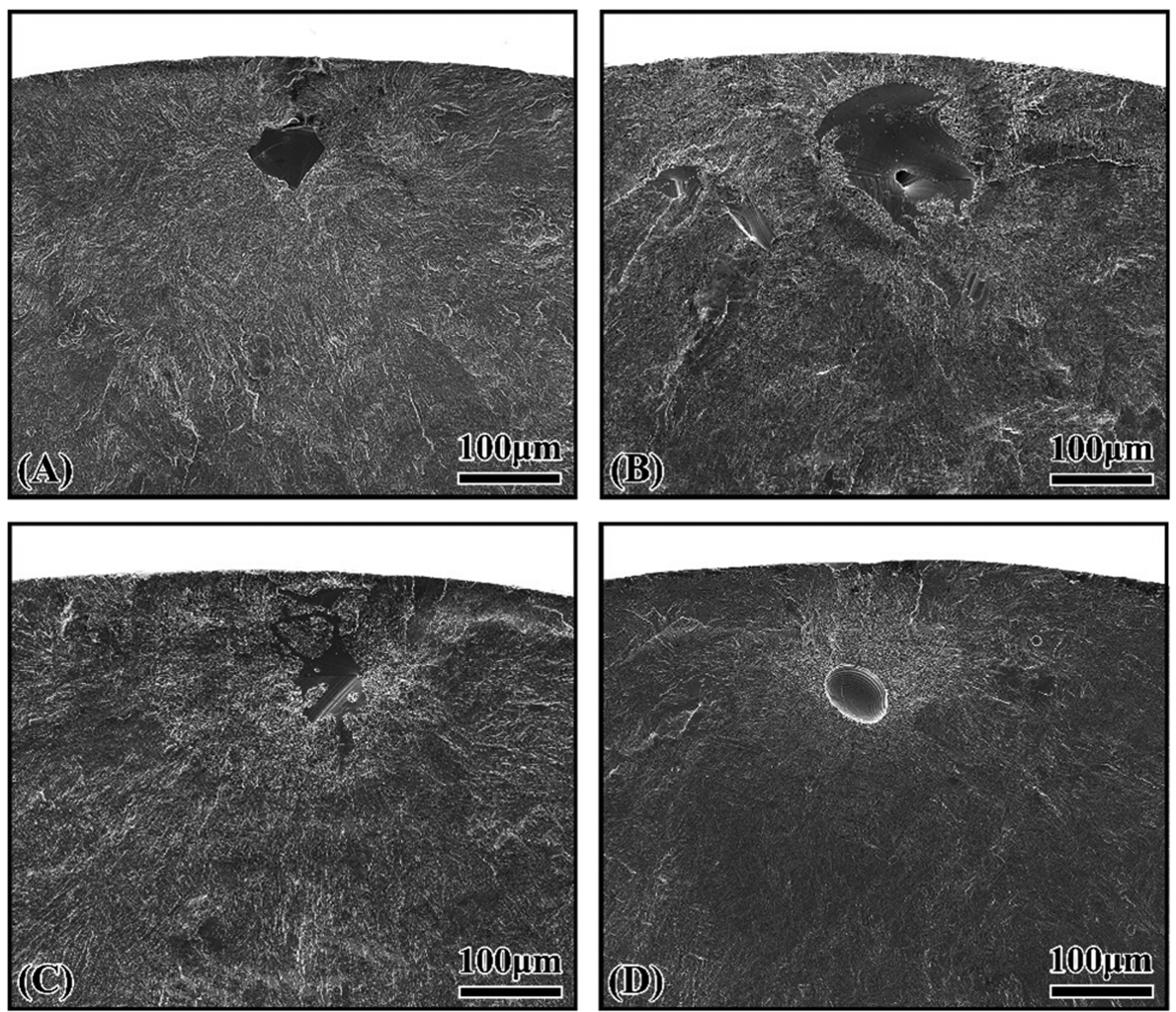

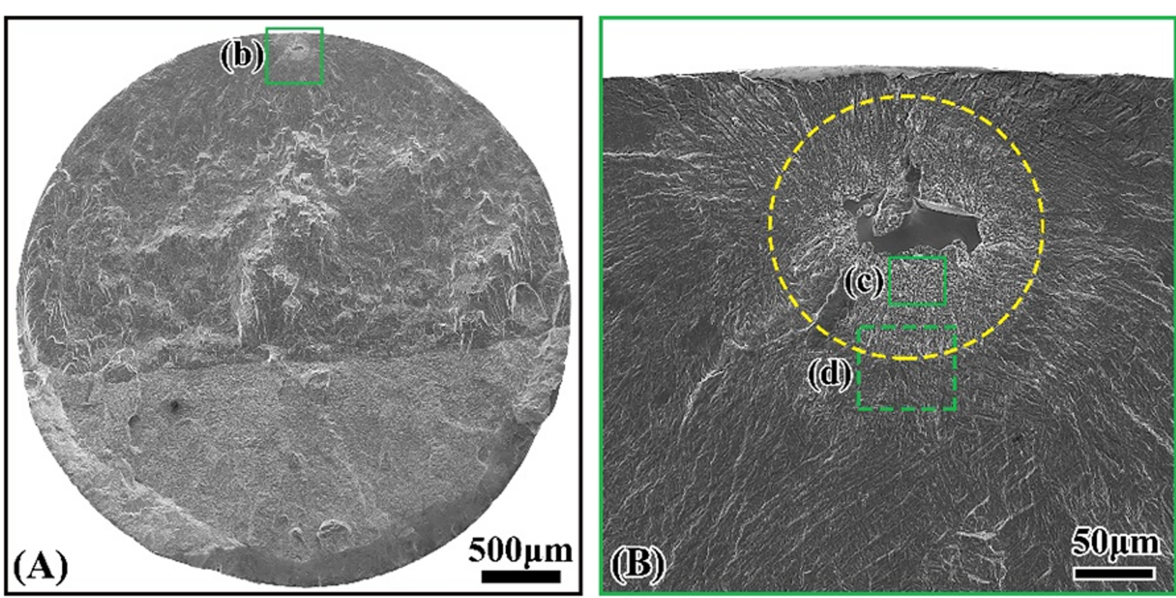

F I G URE 13 Fracture surface of a Group 7 specimen failed in very-high-cycle fatigue (VHCF) regime $\left(\sigma_{\mathrm{a}}=275 \mathrm{MPa}\right.$ and $\left.N_{\mathrm{f}}=5.09 \times 10^{7}\right)$ :

(A) whole fracture surface;

(B) enlargement of crack initiation region of marked square in (A); (C) RA morphology of marked square in (B) and (D) rough area (RA) boundary morphology of marked dashed square in (B) [Colour figure can be viewed at wileyonlinelibrary.com]
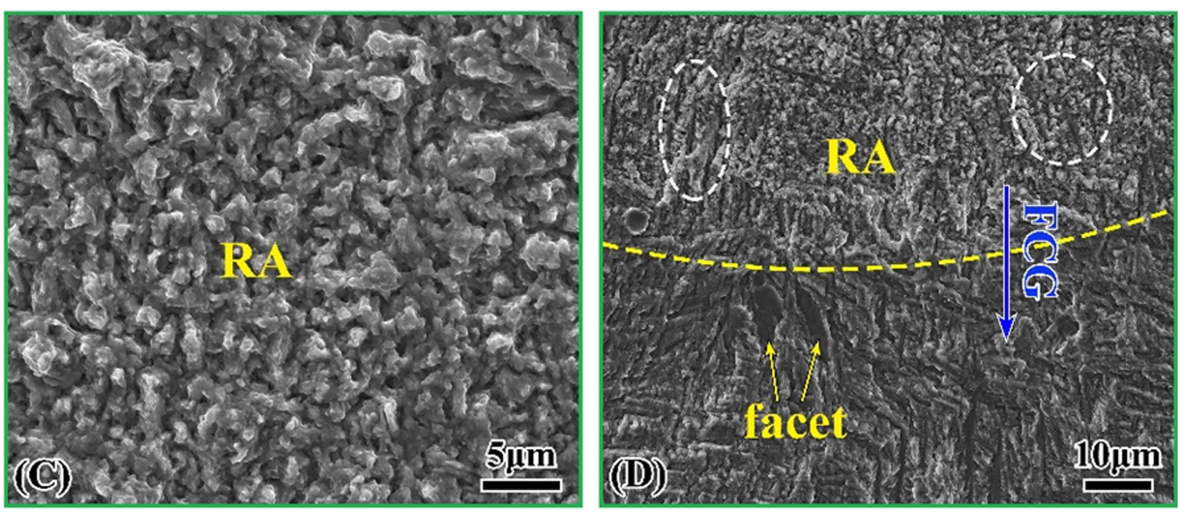

At the end, it is worth mentioning that fatigue failures are always controlled by the largest defect. In this paper, $R_{\mathrm{D}}$ is used as a parameter to characterize the porosity situation for the specimens prepared by different combinations of SLM processing factors. Here, it is considered that the size distribution of the defects or the statistical possibility of the defect size has a similarity for the specimen groups; namely, the specimen group that possesses a large value of $R_{\mathrm{D}}$ will have a large possibility of containing large defects and vice versa. In the present case, the parameter of $R_{\mathrm{D}}$ can act as a measure to reflect the porosity level of different specimen groups thus to characterize the situation of porosity or defects induced by different combinations of SLM processing parameters. The results of the tensile and fatigue properties for the specimens made by different combinations of SLM processing parameters vary with the value of $R_{\mathrm{D}}$, which indicates that $R_{\mathrm{D}}$ is possible for the description of the relationship among processing parameters, resulted defects and mechanical properties.

\section{4 | CONCLUSIONS}

The main goal of the present investigation is to clarify the influence of SLM processing parameters on HCF and VHCF behaviour of a titanium alloy. The findings presented in this investigation lead to the following conclusions:

1. The OED of nine groups of specimens together with the ANOVA has been adequately implemented to find the optimal combination of SLM processing parameters. The results clarify that the influence of individual parameter on the porosity of the SLMed specimens lining up in order is laser power $>$ hatch spacing $>$ layer thickness $>$ scan speed. The anticipated optimal combination of the processing parameters is laser power $160 \mathrm{~W}$, layer thickness $30 \mu \mathrm{m}$, scan speed $1000 \mathrm{~mm} \mathrm{~s}^{-1}$ and hatch spacing $0.07 \mathrm{~mm}$, which gives the input laser energy density of $76.2 \mathrm{~J} \mathrm{~mm}^{-3}$. The results of validation group with the optimal combination of processing parameters possess the lowest porosity, the highest tensile properties and the highest fatigue strength at $\mathrm{HCF}$ and $\mathrm{VHCF}$ regimes.

2. Yield strength and ultimate strength are less affected by the variation of porosity for the SLMed specimens. However, the value of total elongation is significantly degraded with the increase of porosity for the SLMed specimens.

3. The fatigue performance of the SLMed specimens in HCF and VHCF regimes is gradually affected by the 
porosity with the fatigue strength markedly decreasing with the increase of porosity percentage. At $10^{7}$ failure cycles, the highest fatigue strength (300 MPa) for the specimen group (validation group) with the smallest porosity $(0.20 \%)$ is more than three folds of the lowest fatigue strength ( $90 \mathrm{MPa}$ ) for the specimen group with the largest porosity (8.03\%); and at $10^{8}$ failure cycles, the fatigue strength is $280 \mathrm{MPa}$ for the former and $90 \mathrm{MPa}$ for the latter.

4. The trend of $S-N$ curves covering HCF and VHCF regimes varies for the specimen groups with different values of porosity. For the specimen group with high porosity, the $S$ - $N$ curve is of a 'single-wise' trend with a fatigue limit. For the specimen group with low porosity, the $S$ - $N$ curve is of a 'step-wise' trend.

5. The majority of fatigue crack initiation sites are at lackof-fusion defects of the SLMed specimens. In HCF regime, fatigue crack tends to initiate from specimen surface, whereas in VHCF regime, internal crack initiation prevails. RA surrounding crack origin is the characteristic region of crack initiation at $\mathrm{VHCF}$ regime.

\section{ACKNOWLEDGEMENTS}

Financial supports from the National Natural Science Foundation of China (11932020) and from the Strategic Priority Research Program of the Chinese Academy of Sciences (XDB22040503 and XDB22020201) are greatly acknowledged.

\section{NOMENCLATURE}

\section{A test factor}

AM additive manufacturing

ANOVA analysis of variance

$D F \quad$ degree of freedom

E energy density

FiE fish-eye

$h \quad$ hatch spacing

HCF high-cycle fatigue

HIP hot-isostatic-pressed

$K_{m j} \quad$ sum of experimental data corresponding to mth level and jth factor

LCF low-cycle fatigue

$M S \quad$ mean square of a factor

$N_{\mathrm{f}} \quad$ number of cycles to failure

OED orthogonal experiment design

OM optical microscopy

$P \quad$ laser power

$R \quad$ stress ratio

RA rough area

$R_{\mathrm{D}} \quad$ porosity

$S_{\mathrm{A}} \quad$ sum of squares correlated to test factor A

$S_{\mathrm{E}} \quad$ sum of squares of the errors correlated to all test factors

$\begin{array}{ll}\text { SEM } & \text { scanning electron microscopy } \\ S I G & \text { significance value } \\ \text { SLM } & \text { selective laser melting } \\ S S & \text { sum of squares in relation to a factor } \\ S_{\mathrm{T}} & \text { sum of squares of the variance } \\ t & \text { layer thickness } \\ T & \text { sum of porosity data } \\ v & \text { scan speed } \\ \text { VHCF } & \text { very-high-cycle fatigue } \\ x_{i t} & \text { tth measured porosity of ith group } \\ \alpha & \text { significance level } \\ \varepsilon_{\mathrm{t}} & \text { total elongation } \\ \rho_{\mathrm{e}} & \text { measured density } \\ \rho_{\mathrm{n}} & \text { nominal densitys } \\ \sigma_{\mathrm{a}} & \text { stress amplitude } \\ \sigma_{\mathrm{u}} & \text { ultimate tensile strength } \\ \sigma_{\mathrm{y}} & \text { yield strength }\end{array}$

ORCID

Guian Qian (1) https://orcid.org/0000-0003-0487-9780

Youshi Hong (1) https://orcid.org/0000-0003-3425-6808

\section{REFERENCES}

1. Abe F, Osakada K, Shiomi M, Uematsu K, Matsumoto M. The manufacturing of hard tools from metallic powders by selective laser melting. J Mater Process Technol. 2001;111:210-213.

2. Kruth JP, Levy G, Klocke F, Childs THC. Consolidation phenomena in laser and powder-bed based layered manufacturing. CIRP Ann. 2007;56:730-759.

3. Yadroitsev I, Krakhmalev P, Yadroitsava I, Johansson S, Smurov I. Energy input effect on morphology and microstructure of selective laser melting single track from metallic powder. J Mater Process Technol. 2013;213:606-613.

4. Rodriguez OL, Allison PG, Whittington WR, et al. Dynamic tensile behavior of electron beam additive manufactured Ti6Al4V. Mater Sci Eng A. 2015;641:323-327.

5. Kasperovich G, Hausmann J. Improvement of fatigue resistance and ductility of Ti-6Al-4V processed by selective laser melting. J Mater Process Technol. 2015;220:202-214.

6. Leyens C, Peters M. Titanium and titanium alloys: Fundamentals and applications. Wiley-VCH; 2003.

7. Kasperovich G, Haubrich J, Gussone J, Requena G. Correlation between porosity and processing parameters in Ti-6Al-4V produced by selective laser melting. Mater des. 2016;105:160-170.

8. Gong H, Rafi K, Gu H, Starr T, Stucker B. Analysis of defect generation in Ti-6Al4V parts made using powder bed fusion additive manufacturing processes. Addit Manuf. 2014;1:87-98.

9. Lampeas G, Diamantakos I, Ptochos E. Multifield modelling and failure prediction of cellular cores produced by selective laser melting. Fatigue Fract Eng Mater Struct. 2019;42:1534-1547.

10. Qiu C, Panwisawas C, Ward M, Basoalto H, Brooks J, Attallah M. On the role of melt flow into the surface structure and porosity development during selective laser melting. Acta Mater. 2015;96:72-79.

11. Stern F, Kleinhorst J, Tenkamp J, Walther F. Investigation of the anisotropic cyclic damage behavior of selective laser melted 
AISI 316L stainless steel. Fatigue Fract Eng Mater Struct. 2019; 42:2422-2430.

12. Xue G, Ke L, Zhu H, Liao H, Zhu J, Zeng X. Influence of processing parameters on selective laser melted $\mathrm{SiCp} / \mathrm{AlSi} 10 \mathrm{Mg}$ composites: densification, microstructure and mechanical properties. Mater Sci Eng A. 2019;794:138155.

13. Yates JR, Efthymiadis P, Antonysamy AA, Pinna C, Tong J. Do additive manufactured parts deserve better? Fatigue Fract Eng Mater Struct. 2019;42:2146-2154.

14. Xu W, Sun S, Elambasseril J, Liu Q, Brandt M, Qian M. Ti-6Al-4V additively manufactured by selective laser melting with superior mechanical properties. JOM. 2015;67:668-673.

15. Liu J, Sun Q, Zhou C, et al. Achieving Ti6Al4V alloys with both high strength and ductility via selective laser melting. Mater Sci Eng A. 2019;766:138319.

16. Grimm T, Wiora G, Witt G. Characterization of typical surface effects in additive manufacturing with confocal microscopy. Surf Topogr Metrol Prop. 2015;3:014001.

17. Zhang Y, Wu L, Guo X, et al. Additive manufacturing of metallic materials: a review. J Mater Eng Perform. 2018;27:1-13.

18. Akerfeldt P, Pederson R, Antti M. A fractographic study exploring the relationship between the low cycle fatigue and metallurgical properties of laser metal wire deposited Ti-6Al-4V. Int J Fatigue. 2016;87:245-256.

19. Ren Y, Lin X, Guo P, et al. Low cycle fatigue properties of Ti$6 \mathrm{Al}-4 \mathrm{~V}$ alloy fabricated by high-power laser directed energy deposition: experimental and prediction. Int J Fatigue. 2019; 127:58-73.

20. Pegues J, Roach M, Williamson R, Shamsaei N. Surface roughness effects on the fatigue strength of additively manufactured Ti-6Al-4V. Int J Fatigue. 2018;116:543-552.

21. Fatemi A, Molaei R, Simsiriwong J, et al. Fatigue behaviour of additive manufactured materials: an overview of some recent experimental studies on Ti-6Al-4V considering various processing and loading direction effects. Fatigue Fract Eng Mater Struct. 2019;42:991-1009.

22. Kakiuchi T, Kawaguchi R, Nakajima M, Hojo M, Fujimoto K, Uematsu Y. Prediction of fatigue limit in additively manufactured Ti-6Al-4V alloy at elevated temperature. Int $J$ Fatigue. 2019;62:55-61.

23. Wycisk E, Siddique S, Herzog D, Walther F, Emmelmann C. Fatigue performance of laser additive manufactured Ti-6Al-4V in very high cycle fatigue regime up to $10^{9}$ cycles. Front Mater. 2015;72(2):1-8.

24. Günther J, Krewerth D, Lippmann T, Leuders S, Tröster T, Weidner A. Fatigue life of additively manufactured Ti-6Al-4V in the very high cycle fatigue regime. Int J Fatigue. 2017;94: 236-245.

25. Qian G, Li Y, Paolino D, Tridello A, Berto F, Hong Y. Veryhigh-cycle fatigue behavior of Ti-6Al-4V manufactured by selective laser melting: effect of build orientation. Int J Fatigue. 2020;136:105628.

26. Tridello A, Fiocchi J, Biffi CA, et al. Influence of the annealing and defects on the VHCF behavior of an SLM AlSi10Mg alloy. Fatigue Fract Eng Mater Struct. 2019;42:2794-2807.

27. Davim JP. Design of optimisation of cutting parameters for turning metal matrix composites based on the orthogonal arrays. J Mater Proc Tech. 2003;132:340-344.
28. Huang ZQ, Chen Z, Li Q, Jing S, Li G, Tao ZF. Fatigue reliability analysis for vibroseis baseplates. Fatigue Fract Eng Mater Struct. 2016;39:1503-1516.

29. Bester T, Oman S, Nagode M. Determining influential factors for an air spring fatigue life. Fatigue Fract Eng Mater Struct. 2019;42:284-294.

30. Thompson SM, Bian L, Shamsaei N, Yadollahi A. An overview of direct laser deposition for additive manufacturing; Part I: transport phenomena, modeling, and diagnostics. Addit Manuf. 2015;8:36-62.

31. Yadroitsev I, Yadroitsava I, Bertrand P, Smurov I. Factor analysis of selective laser melting process parameters and geometrical characteristics of synthesized single tracks. Rapid Prototyp J. 2012;18:201-208.

32. Thijs L, Verhaeghe F, Craeghs T, Van Humbeeck J, Kruth J. A study of the microstructural evolution during selective laser melting of Ti-6Al-4V. Acta Mater. 2010;58:3303-3312.

33. Oehlert GW. A First Course in Design and Analysis of Experiments. Kluwer Academic Publishers; 2010.

34. Liu J, Zeng W, Lai Y, Jia Z. Constitutive model of Ti17 titanium alloy with lamellar-type initial microstructure during hot deformation based on orthogonal analysis. Mater Sci Eng A. 2014; 597:387-394.

35. Mao Z, Zhang D, Jiang J, Fu G, Zhang P. Processing optimization, mechanical properties and microstructural evolution during selective laser melting of $\mathrm{Cu}-15 \mathrm{Sn}$ high-tin bronze. Mater Sci Eng A. 2018;721:125-134.

36. Beese AM, Carroll BE. Review of mechanical properties of Ti$6 \mathrm{Al}-4 \mathrm{~V}$ made by laser-based additive manufacturing using powder feedstock. JOM. 2016;68:724-734.

37. Liu X, Sun C, Hong Y. Effects of stress ratio on high-cycle and very-high-cycle fatigue behavior of a Ti-6Al-4V alloy. Mater Sci Eng A. 2015;622:228-235.

38. Pan X, Hong Y. High-cycle and very-high-cycle fatigue behaviour of a titanium alloy with equiaxed microstructure under different mean stresses. Fatigue Fract Eng Mater Struct. 2019; 42:1950-1964.

39. Heinz S, Eifler D. Crack initiation mechanisms of Ti6Al4V in the very high cycle fatigue regime. Int J Fatigue. 2016;93: 301-308.

40. Hong Y, Liu X, Lei Z, Sun C. The formation mechanism of characteristic region at crack initiation for very-high-cycle fatigue of high-strength steels. Int J Fatigue. 2016;89:108-118.

41. Hong Y, Sun C. The nature and the mechanism of crack initiation and early growth for very-high-cycle fatigue of metallic materials-an overview. Theor Appl Fract Mech. 2017;92: 331-350.

How to cite this article: Du L, Qian G, Zheng L, Hong Y. Influence of processing parameters of selective laser melting on high-cycle and very-highcycle fatigue behaviour of Ti-6Al-4V. Fatigue Fract Eng Mater Struct. 2021;44:240-256. https://doi.org/ $\underline{10.1111 / \text { ffe. } 13361}$ 